\title{
Probabilistic and deterministic results of the ANPAF analog model for Spanish wind field estimations
}

\author{
A. Pascual ${ }^{\text {,a }}$, F. Valero a, M.L. Martín ${ }^{\text {b }}$, A. Morata ${ }^{\text {c }}$, M.Y. Luna ${ }^{\text {c }}$ \\ ${ }^{a}$ Dpto. Astrofisica y CC. de la Atmósfera, Facultad de CC Físicas, Universidad Complutense de Madrid, Ciudad Universitaria s/n. 28040 Madrid, Spain \\ b Dpto. Matemática Aplicada, Escuela Universitaria de Informática de Segovia, Universidad de Valladolid, Pza. Sta. Eulalia 9-11. 40005 Segovia, Spain \\ c Agencia Estatal de Meteorología. C/ Leonardo Prieto Castro, 8. 28040 Madrid, Spain
}

\section{A R T I C L E I N F O}

\section{Article history:}

Received 27 June 2011

Received in revised form 24 January 2012

Accepted 26 January 2012

\section{Keywords:}

Daily mean wind speed

Daily wind gust

Principal component analysis

Geopotential height

Analog model

Deterministic and probabilistic tools

\begin{abstract}
A B S T R A C T
The purpose of this work is to obtain daily mean wind speed and wind gust estimations by means of the analog model. To do this, three data sets have been used: daily $1000 \mathrm{hPa}$ geopotential height field over the North Atlantic, observational daily mean wind speed and observational daily gust wind speeds in Spain. Previously to the analog method, a Principal Component Analysis is used to reduce the dimensionality of the large-scale atmospheric database. Here, the analog method is based on finding in the historic geopotential height data base, a PC subset of large-scale atmospheric patterns that are the most similar to a large-scale atmospheric pattern used as input. In the algorithm process of the analog model, two Euclidean metrics in two different distances used as weighting functions are defined and analyzed for finding the best analogs. Thus, similar atmospheric situations to any particular atmospheric situation to be modeled have been determined and from them, several and different wind fields have been estimated, to characterize the wind fields in Spain. Several deterministic and probabilistic results are shown. Results of bias, spatial correlations and root mean squared errors between the estimated and observational wind fields are displayed, evaluating the model skilful for predicting mean wind and gusts. The probabilistic results are shown by means of Brier Skill Scores, rank histograms and reliability diagrams. The procedure used in this paper to find analogs, reducing previously the dimensionality of the large-scale atmospheric data and obtaining PCs, has been revealed as a good technique to find similar patterns to any particular one.
\end{abstract}

(c) 2012 Elsevier B.V. All rights reserved.

\section{Introduction}

During the last decades, the world is seeing a progressive increase of interest on using sustainable and clean renewable energies. Wind energy is seen today as a proven useful technology and many efforts are leading to use high potential wind energy resources. In that sense, the scope of several research projects have been forecasting, modeling and wind data assimilating for a safe large-scale wind power integration in order to finally be utilized by the end-users. Within

\footnotetext{
* Corresponding author at: Astrofísica y CC. de la Atmósfera, Facultad de CC Físicas, Universidad Complutense de Madrid, Ciudad Universitaria s/n. 28040 Madrid, Spain. Tel./fax: + 34913945088.

E-mail address: a.depascual@fis.ucm.es (A. Pascual).
}

the European Project SafeWind, several methods have been proposed in order to analyze the overall wind energy situation over an area of interest by spatial-temporal analyses of meteorological and wind power measurements. The final analysis could subsequently then be used for nowcasting wind power over the whole area, and for data assimilation purposes (in order to update and improve wind power predictions) for better understanding the spatial-temporal characteristics of prediction errors, or for issuing "global" warnings related to expected accuracy of weather and wind power forecasts over the area considered. In particular, the project analyses the atmospheric circulation patterns, particularly those dealing with atmospheric patterns conducive to risky meteorological situations related to extreme wind events, that are especially important for wind energy applications 
(Palutikof et al., 1987; Thuillier, 1987; Zuranski and Jaspinka, 1996).

Multivariate techniques have been revealed as good methods to obtain the most significant variability atmospheric patterns as well the relationships between large-scale fields and observational data (Wilby, et al., 1998; Xoplaki et al. 2003a, b, 2004; Vrac et al., 2007; Paul et al., 2008; Busuioc et al., 2008; Li and Smith, 2009). In the Iberian Peninsula, several techniques have been used for analyzing the relationships between surface atmospheric circulation patterns and precipitation or temperature (Corte-Real et al., 1998; Trigo and DaCamara, 2000; Luna et al., 2001; Valero et al., 2004; Martín et al., 2004; Martín et al., 2006; Martín et al., 2010; García-Ortega et al., 2011). Signal processing techniques and other methods have been also used for obtaining the most significant variability modes of the Iberian precipitation (Martín et al., 2001, 2004; Mosmann et al., 2004; Morata et al., 2006; Sotillo et al., 2006, Aznar et al., 2010). However, these techniques have been insufficiently applied to wind variables. Martín et al. (2011a, 2011b) have analyzed the springtime relationships between large-scale variability patterns and wind gusts and wind speeds in Spain, identifying the main atmospheric circulation patterns linked to wind gust and wind speed anomaly configurations. Pascual et al. (2010) have started to analyze the wintertime daily surface wind speed in Spain by means of principal components using observations, highlighting the Spanish wind speed behavior in the main modes of variability. Relationships between the largescale atmospheric modes and the observational local wind speeds are also studied in terms of the cumulated frequency values of wind speed associated with the extreme scores of the obtained large-scale modes, to underline those large-scale atmospheric patterns more dominant in the wind field in Spain.

The improvement of meteorological forecasts of wind by means of dynamic modeling has been progressing by means of limited area models or ensemble prediction systems in other research projects (ANEMOS, ANEMOS.plus). However, this methodology bears high computational costs. In order to overcome this problem, the analog method for predicting time series can be used (Lorenz, 1969). With this method, local prediction models are obtained finding in a set of historic data similar situations to a particular situation (Hastie et al., 2001; Fernandez and Saenz, 2003; Fraedrich et al., 2003). This technique has been implemented for both climatic anomaly predictions (Zorita and von Storch, 1999; Wilby and Wigley, 1997) and short-range prediction (Dool van den, 1989), revealing as an alternative to other more complex models with high computational cost. In the framework of the European Project SafeWind, the authors have been developing several works based on multivariate methodologies for obtaining atmospheric situations analog to a situation associated with extreme winds (Pascual et al., 2010). One of the final purposes of this European Project is to develop a statistical downscaling model (ANPAF: ANalog PAttern Finder) for diagnosing large-scale atmospheric circulation patterns and subsequently estimating extreme wind probabilities. In the present paper, from an atmospheric circulation pattern set obtained by multivariate methodology applied to a largescale atmospheric circulation field, estimations of wind fields are obtained by means of the analogs methodology.
The present study is focused on obtaining wind speed and wind gust estimations in Spain by means of the analog methodology applied to large-scale atmospheric data. To do this, a principal component analysis is previously applied to the atmospheric circulation field in order to reduce the dimensionality of the large-scale atmospheric data. The multivariate techniques have been successfully used by the authors (Martín et al., 2004; Sotillo et al., 2006; Morata et al., 2006; Morata et al., 2008; Valero et al., 2009; Martín et al., 2011a, $2011 b)$ in other studies to gain a better insight into the seasonal relation between large-scale circulation anomalies and regional variable fluctuations, giving evidence of the influence of several North Atlantic teleconnection patterns of low-frequency on the variability of the regional variables in the Western Mediterranean area.

Once the large-scale atmospheric statistical modes have been obtained by means of multivariate techniques, the analog method is applied. In the algorithm process of any analog model, a weighting function that considers the similitude between any given situation and the past situations is needed. To take into account this similitude measurement, there have been several strategies to be considered (Cofiño, 2004; Sordo, 2006; Zhu et al., 2011), taking into account the computational capacity. In the present work, several distance functions based on the principal component scores have been proposed and analyzed. These distance functions are used to find the most similar atmospheric situations to a given atmospheric situation used as input in the analog model. Once the most similar patterns have been found, the final estimations can be made by using different approaches: using a simply analog, averaged analogs or neural networks (Fraedrich and Rückert, 1998; Zorita and von Storch, 1999; Cofiño, 2004; Gutierrez et al., 2004). In approaches where more than one analog are used, the number of analogs included for giving an estimation has an important relevance on the results, as analogs should make up a robust statistical set. Here, a sensitivity analysis has been done in order to select the optimum number of analogs that minimizes the model errors. On the other hand, the obtained analog set might include more useful statistical information as it can be the expected variability of the estimations. A statistical study of the analog values must therefore provide a distribution of the expected values. At this point, some statistical probabilistic tools, such as rank histograms, reliability diagrams and probabilistic skill scores, are used in order to assess the skill of the model for estimating probability density functions.

The study is organized as follows. A brief description of the data sets and the diverse methods applied to the original datasets is given in Section 2, proposing as well the distance functions to be used to find analogs. Sections 3 and 4 are devoted to analyze the analog results for both the large-scale atmospheric field and the Spanish mean wind speed and wind gust, in terms of some deterministic and probabilistic tools. The summary and discussion of the main results are drawn in Section 5.

\section{Data and methods}

Several data sets have been used in this study: daily $1000 \mathrm{hPa}$ geopotential height at 12:00 UTC (Z1000), daily mean wind speed (MWS) data and daily wind gust (WGU) data over Spain during all the year distributed in the four 
seasons: winter (DJF), autumn (SON), spring (MAM) and summer (JJA). Z1000 data are a product of the ERA40 Reanalysis (Gibson et al., 1997; Simmons and Gibson, 2000). The Z1000 data are given on a $1.2^{\circ} \times 1.2^{\circ}$ latitude $\times$ longitude grid, spanning a $20^{\circ} \mathrm{N}$ to $60^{\circ} \mathrm{N}$ of latitude and from $51.5^{\circ}$ $\mathrm{W}$ to $15.5^{\circ} \mathrm{E}$ of longitude. Thus, 1995 spatial nodes or grid points are considered. The WGU data used in this paper consists of 73 time series of daily gusts and the MWS data consists of time series of daily mean wind speed from 23 sites in Spain. These wind data come from in-situ measurements of the station network of the Spanish Meteorological Service (Agencia Estatal de Meteorología, AEMET) and the spatial distribution of stations is displayed in Fig. 1. Both the observational and reanalysis data bases present different time coverages (WGU and MWS from 1933 to 2008, ERA40 Reanalysis from 1957 to 2002). However, taking into account the observational data quality and the methodology employed in this paper, the three datasets finally cover the common period from 1971 to 2002.

The analog methodology has been widely used in the climatic anomaly predictions (Zorita and von Storch, 1999; Wilby and Wigley, 1997) and in the short-range prediction (Barnett and Preinsendorfer, 1978; Dool van den, 1994; Fernandez and Saenz, 2003), though its use has been as a prognostic and diagnosis tool. Concerning forecasting, the analog method has been used in predicting tropical cyclone tracks by means of ensembles (Sievers et al., 2000; Fraedrich et al., 2003). The idea is based on the comparison between the field of an input variable and the other input variable to determine the most similar among them. Here $\mathrm{Z} 1000$ is used both as input as historical field with which to be compared. Because of the great amount in the freedom degrees of any large-scale atmospheric field it is needed to use long datasets, presenting thus such methodology this disadvantage. However, many freedom degrees can be considered as associated to noise. To reduce the inherent noise in the data, these have been previously subjected to a smoothing process.
In order to use the significant information in the analog method, a principal component analysis (PCA) was previously applied to the Z1000 data base (Preisendorfer, 1998; Joliffe, 1986). The PCA has been proven to be a reliable method for data reduction and for examining the variance structure. Let $\mathbf{F}(n \times p)$ be a m-dimensional matrix of $n$ independent observations expressed as anomalies and $p$ random elements; in our case, $\mathbf{F}$ represents the anomalies of the Z1000 field. The objective of the PCA is to find uncorrelated linear combinations of different variables explaining maximum variance; thus, the purpose is to find a unit-length direction $\mathbf{u}=\left(u_{1}, \ldots, u_{p}\right)^{\mathrm{T}}$ such that $F \mathbf{u}$ present maximum variability. The covariance matrix of $F$ data is diagonalized in order to find the eigenvectors $\mathbf{u}_{\mathrm{k}}$. The corresponding eigenvalue $\lambda_{k}^{2}$ gives a measure of the variance of the data taken into account the direction $\mathbf{u}_{\mathrm{k}}$. The projection of the anomaly field $F$ onto the $\mathrm{k}^{\text {th }} \mathbf{u}_{\mathrm{k}}=\left(u_{\mathrm{k} 1}, \ldots, u_{\mathrm{kp}}\right)^{\mathrm{T}}$, is the $\mathrm{k}^{\text {th }}$ Principal Component (PC) whose elements are given by

$s_{t k}=\sum_{j=1}^{p} f_{t j} u_{k j}$

In literature, the eigenvectors $\mathbf{u}$ are also known as PC loadings and the principal components are known as amplitudes, PC time series or scores. In this paper, we use the terminology with loadings and scores. Eq. (1) is mainly useful when one want to use the PCA as a method for data dimensionality reduction; this is attained by truncating the above sum,

$s_{t k}^{\prime}=\sum_{j=1}^{r} f_{t j} u_{k j}$

where $r(r<p)$ is the number of retained PCs, avoiding some part of variability not contained in the retained first patterns and supposed as noise.

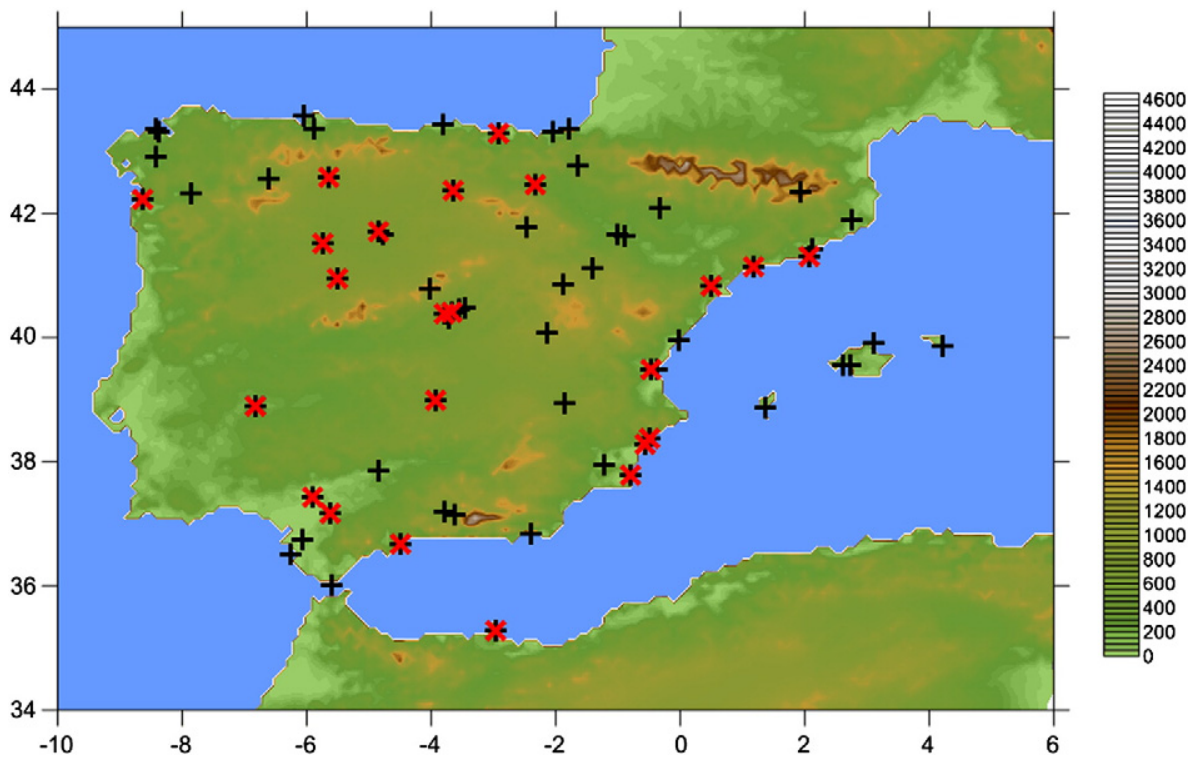

Fig. 1. The Iberian Peninsula with its orography detailed with the mean wind speed stations in red crosses and the wind gust stations in black crosses. The $\mathrm{x}$-axis corresponds to longitude, positive (negative) for East (West). 


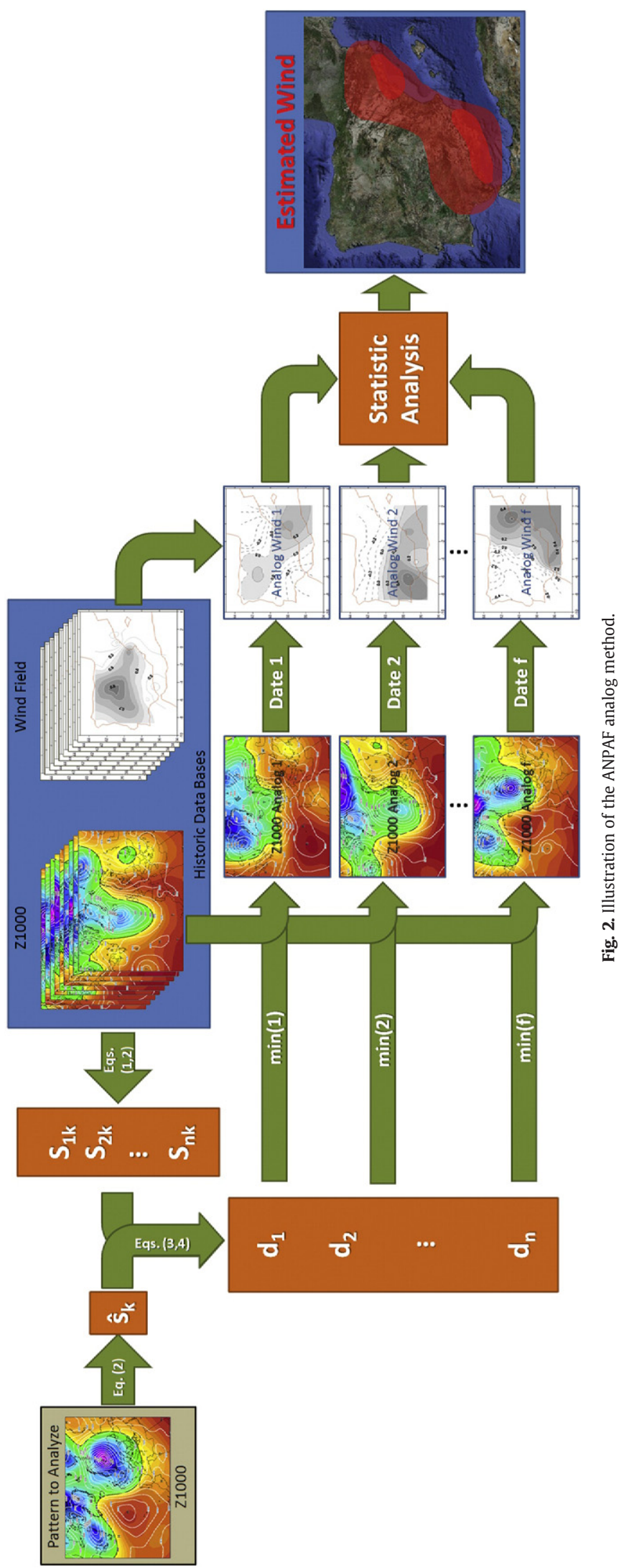


Taking into account all this process, a decomposition of the input field on the vectorial space obtained from the multivariate analysis of a large-scale atmospheric field is made. Thus, $s_{t k}$ corresponds to the whole set of scores of the historic (in our case the Z1000 field from 1971 to 2007) large-scale atmospheric field and $s^{\prime}{ }_{t k}$ represents the corresponding truncated scores obtained by Eq. (2). With this methodology, the number of degrees of freedom has been reduced and significant information in the atmospheric field can be extracted.

The analog method is based on finding, within a historic data base, a set of large-scale atmospheric patterns which are the most similar to a large-scale atmospheric pattern used as input. In the algorithm process of any analog model it is needed a weighting function that considers the similitude of a situation to the past situations. In the present work, several distance functions have been studied and proposed based on the use of the multivariate method. These kinds of techniques allow reducing the dimensionality in finding analogs, maximizing the explaining variance in the data bases. Here, the input pattern is projected onto the loading $\mathrm{k}^{\text {th }} \mathbf{u}_{\mathrm{k}}=\left(u_{\mathrm{k} 1}, \ldots, u_{\mathrm{kp}}\right)^{\mathrm{T}}$, using the Eq. (2) and giving an input estimated score, $-s_{k}$. From the $-s_{k}$, two distance functions are defined taking into account the scores $s_{t k}$ and $s_{t k}^{\prime}$. The scores $s_{t k}$ and $s^{\prime}{ }_{t k}$ are used as elements of a metric that provide a distance between two different fields, giving information about the similarity between them. Here, two Euclidean metrics are defined to be used in the ANPAF analog model:

$d_{t}=\sqrt{\sum_{j=1}^{r} \lambda_{j}\left(s_{j t}--s_{j}\right)^{2}}$

$d_{t}^{\prime}=\sqrt{\sum_{j=1}^{r} \lambda_{j}\left(s_{j t}^{\prime}--s_{j}\right)^{2}}$

where $\lambda_{j}$ is included in the distance function in order to weight the variability of the different retained PCs. The search of ana$\log$ patterns is based on finding a time $t$ that minimizes such distances in the PCA space. In the next section, results associated with the distances are shown.

The analog methodology has been applied to the Z1000 field in order to find several analogs to a particular Z1000 input pattern taking into account the abovedescribed distances. The ANPAF analog method used in this paper can be mainly illustrated in the diagram of Fig. 2. In Fig. 2, an input field score of the Z1000, $-s_{k}$, is compared with the different scores $\left(s_{t k}\right.$ and $\left.s^{\prime}{ }_{t k}\right)$ of the several obtained PCs of the Z1000 field, by means of distance functions $\left(d_{t}\right.$ and $\left.d^{\prime} t\right)$, in order to find the most similar scores throughout the historic scores time record. The procedure is crossvalidated, finding different analogs for a Z1000 input day and repeating the process for all the historic time record. Thus, a set of Z1000 analogs can be obtained. In the next section, results associated with errors in obtaining the analogs are shown. Once the close scores have been obtained, their corresponding dates present associated wind fields that finally can give an estimated wind field in Spain. Wind estimation can be made by using different criterions: a simply analog, averaged analogs, neural networks, ... (Zorita and von Storch, 1999; Cofiño, 2004; Gutierrez et al., 2004). Here, the wind field obtained from the analog methodology has been estimated by using arithmetical means of several analogs. Additionally, a wind probabilistic estimation is also proposed.

\section{Evaluation of analog searching: Z1000 estimation}

Using all the procedures abovedescribed, similar atmospheric situations to a particular input situation to be modeled are determined, and thus, different wind fields derived from the observational daily MWS and WGU are obtained to characterize and estimate the wind field in Spain. The results associated with the analog methodology applied to the Z1000 field are shown. As it is described in the methodology section, the PCs are proposed to adequately represent the original dataset variation without loss of significant information. The PCA has been seasonally applied to the Z1000 field; although the analog methodology is also seasonally applied, the results are evaluated for the entire year. After doing several tests in the whole analog process and following the Kaiser's rule with 1.0 as threshold (Kaiser, 1960), from the original variables the fifteen leading PCs, cumulating more than $80 \%$ of the total variance of the daily $\mathrm{Z1000}$ original field in each season, are retained and considered for the ana$\log$ procedure. Fig. 3 illustrates this part of the analog process. Consequently, an input Z1000 score $-s_{k}$ corresponding to a Z1000 pattern is compared with the different Z1000 scores, $s_{t k}$ and $s_{t k}^{\prime}$, by means of the distance functions, $d_{t}$ and $d^{\prime}{ }_{t}$, and a set of analogs, $A_{t}$ and $A_{t}^{\prime}$, are found. These analog $A_{t}$ 's

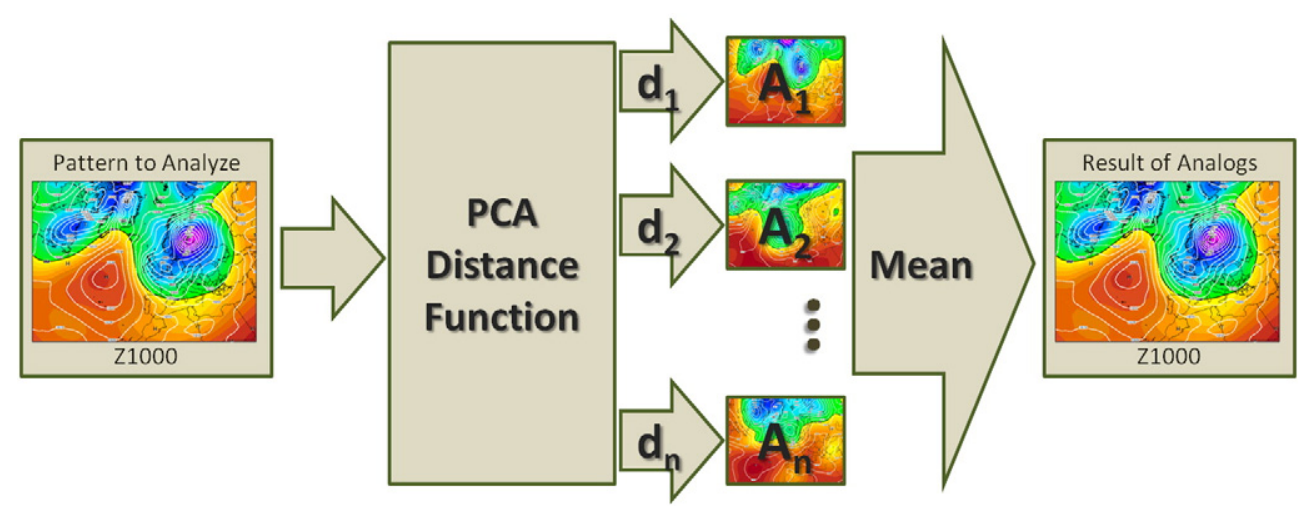

Fig. 3. Illustration of the Z1000 field estimation by analog searching. 


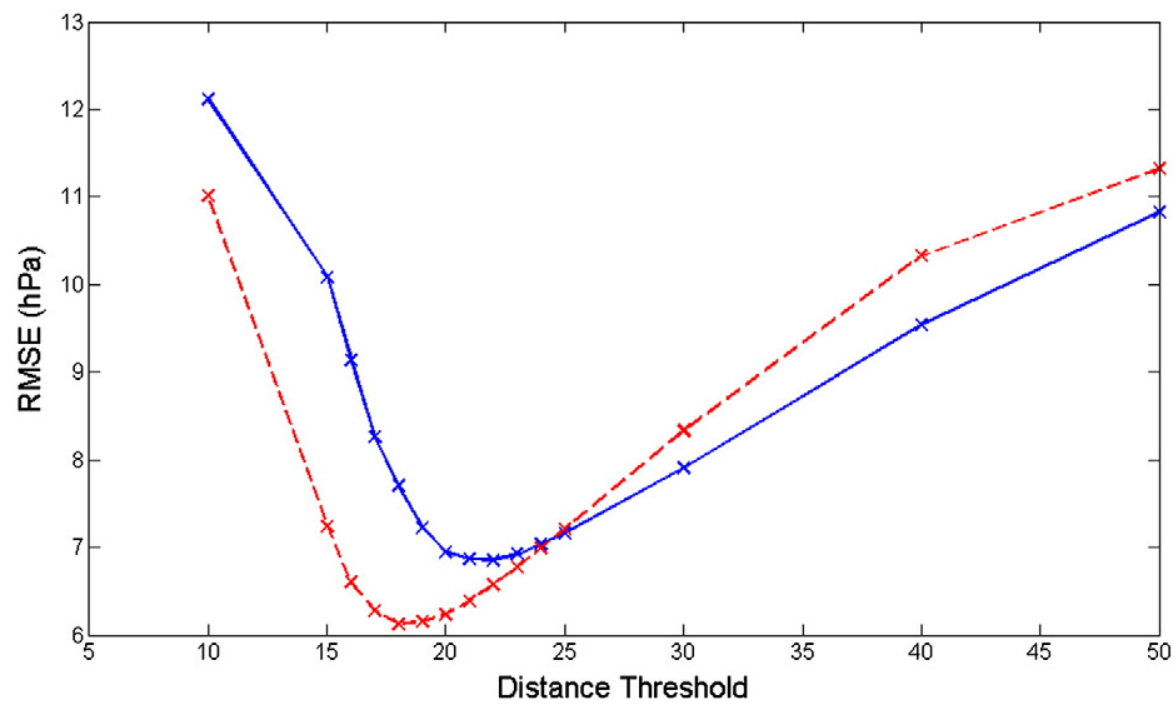

Fig. 4. RMSE values of the Z1000 estimation versus distance thresholds applying the different distances, $d_{t}$ (blue continuous line) and $d^{\prime}{ }_{t}$ (red dashed line).

consist of a subset of the original Z1000 field. From such subset, the averaged analog Z1000 field, Z̃ 1000 , is obtained.

A sensitivity study of the two distance functions has been done in order to select the best analogs of a given Z1000 field, and finally to estimate the wind fields over Spain. The difference between the $s_{t k}$ and $s^{\prime}{ }_{t k}$ time series is quite small; in fact, the correlation between the $s_{t k}$ and $s^{\prime}{ }_{t k}$ is around 0.9. Nevertheless, root mean squared errors (rmse) calculated between the $\tilde{Z} 1000$ field and the input Z1000 field, are derived by means of the metrics in the two distance functions. In order to analyze the results obtained from the two distance functions, two strategies have been used: distance threshold and fixed analog number.

Fig. 4 shows remarkable differences associated with the results of two distances. If distance thresholds are considered, it is also worth to note the differences between $d_{t}$ and $d^{\prime}{ }_{t}$ as the distance thresholds vary. Clearly the rmses related to the distance $d_{t}$ present higher values than those associated with the distance $d^{\prime}$, being the minimum error of $6.12 \mathrm{hPa}$ and having a $d^{\prime}{ }_{t}$ distance threshold of 18 . Assuming that the use of a large threshold value is associated with a huge quantity of analogs (in fact, for a threshold value of 50 , more than 3000 analogs are found), the analog results for such thresholds can correspond to the climatological estimations. Therefore, the analog methodology improves the climatological skill. However, if the distance thresholds are used, particular atmospheric situations could not have associated any analog and so, the methodology cannot give any result. As the threshold diminishes, lesser number of analogs is found and the possibility of obtaining missing results increases (Fig. 5). In fact,

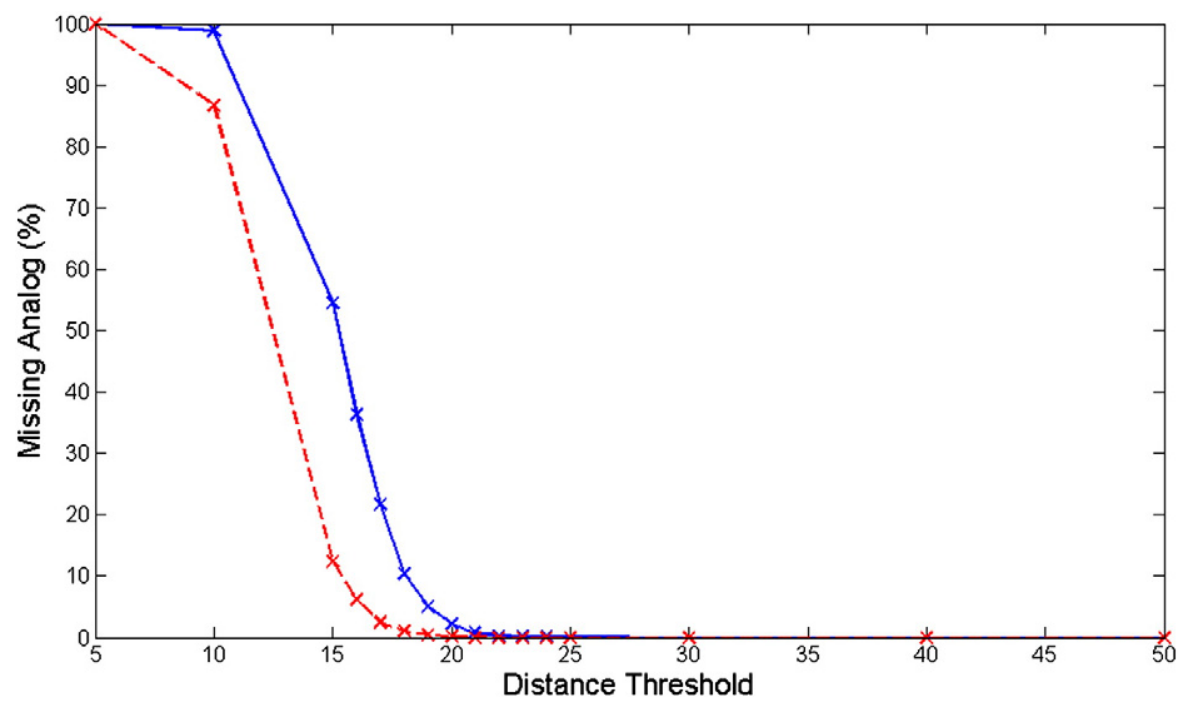

Fig. 5. Missing analogs versus distance thresholds for the different distances, $d_{t}$ (blue continuous line) and $d_{t}^{\prime}$ (red dashed line). 


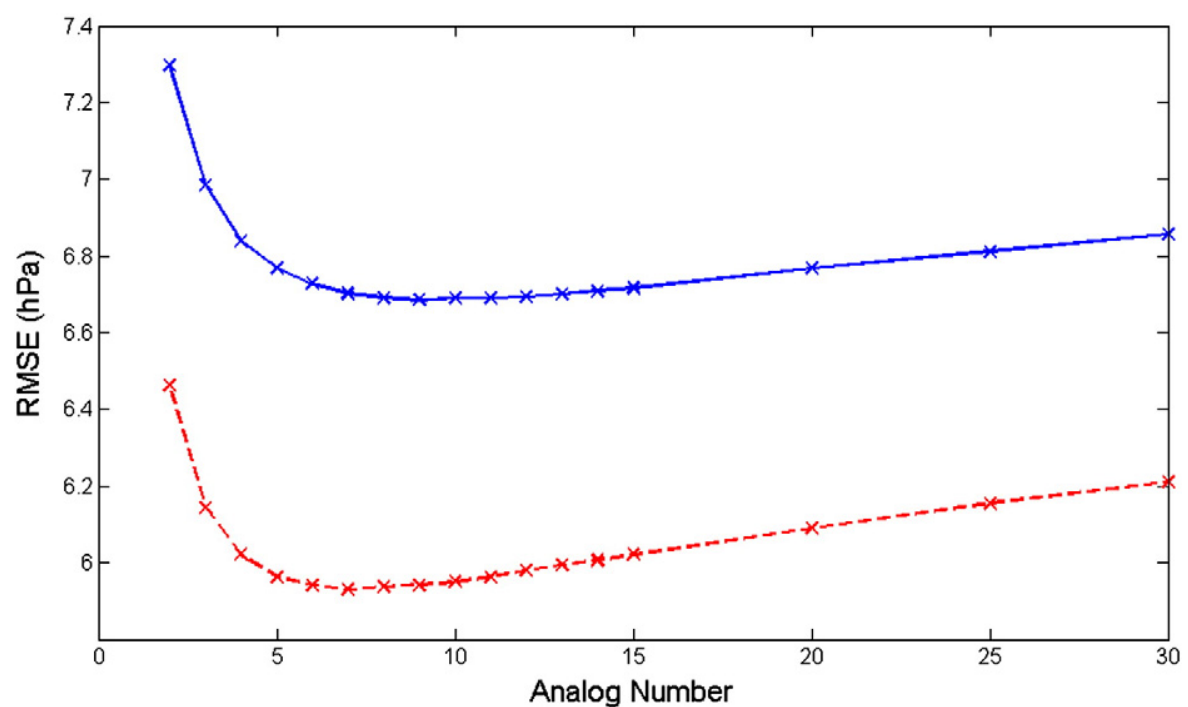

Fig. 6. RMSE values of the Z1000 estimation versus analog number applying different distances, $d_{t}$ (blue continuous line) and $d^{\prime}{ }_{t}$ (red dashed line).

the thresholds minimizing the rmses (Fig. 4) correspond to missing results (Fig. 5) of $0.26 \%$ and $1.11 \%$ for $d_{t}$ and $d_{t}^{\prime}$, respectively.

In order to avoid the handicap related to the missing results that shows the use of a distance threshold, a different approach based on a fixed number of analogs is proposed (Fig. 6). It is evident the difference between the results associated with the two distances. While the rmses related to the distance $d_{t}$ range between 6.7 and $7.3 \mathrm{hPa}$, the corresponding ones of the distance $d^{\prime}{ }_{t}$ vary up to $6.5 \mathrm{hPa}$, highlighting the better skill of the latter distance in representing the input Z1000 field. The rmses maintain high values for a number of analogs lesser than 5 , being remarkable the growing of the errors as the selected analog number is increasing. Although the most favorable number of analogs to be used is found between 5 and 10 , it will be suitable to use more than 10 analogs that lesser than 5 ones, because the larger errors in the latter case. Fig. 6 simply shows the rmse results up to 30 analogs; however, the growing of errors has been also estimated for a high number of analog, showing a slight

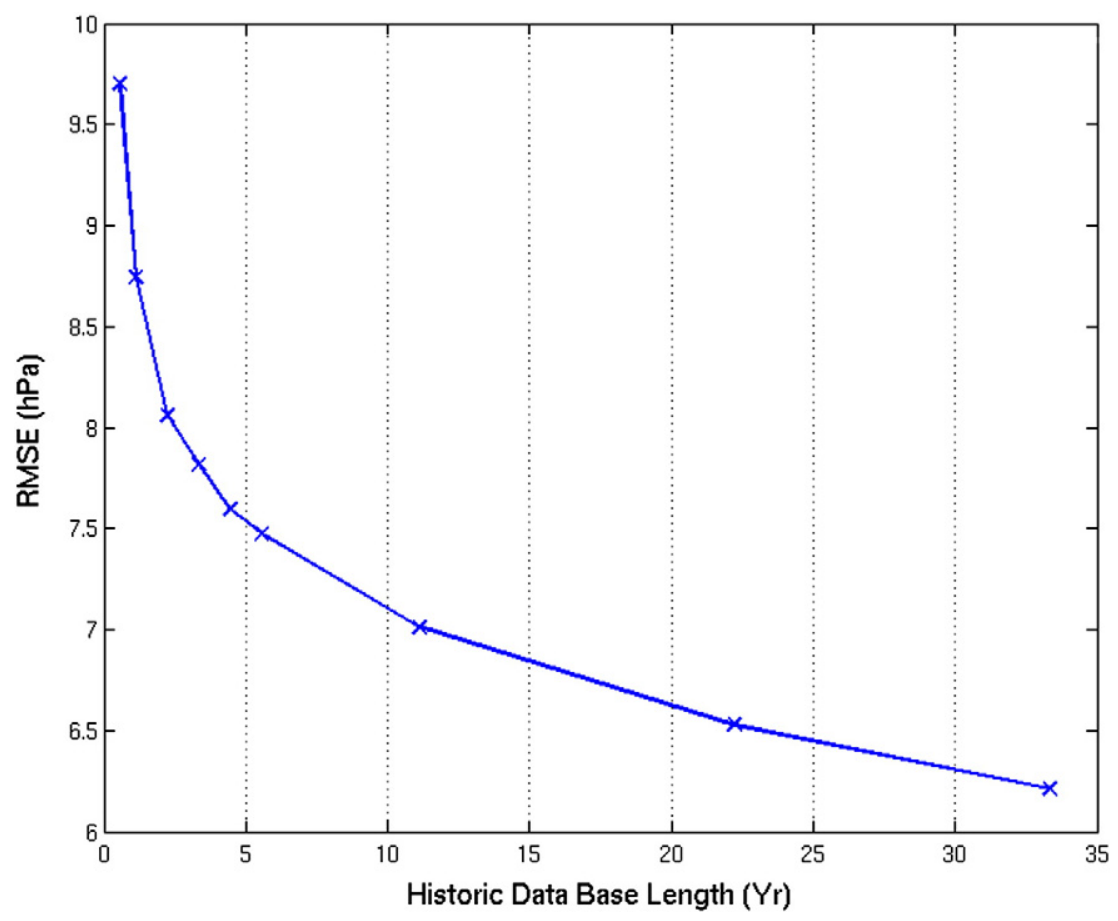

Fig. 7. RMSE values of the Z1000 estimation versus time record of Z1000. 
a

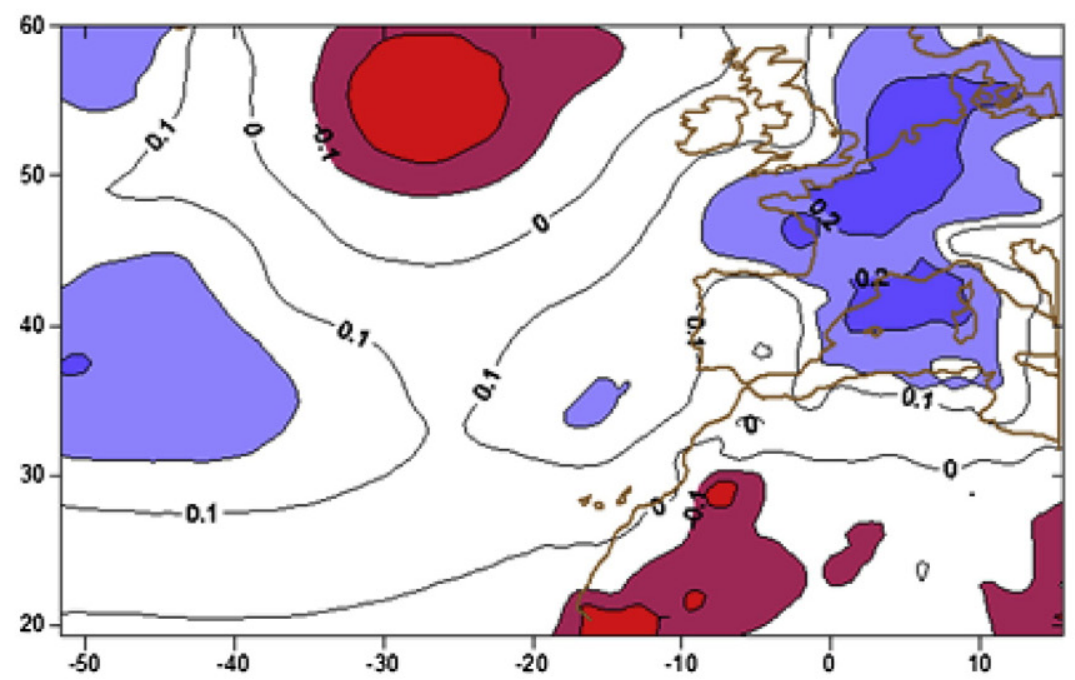

b

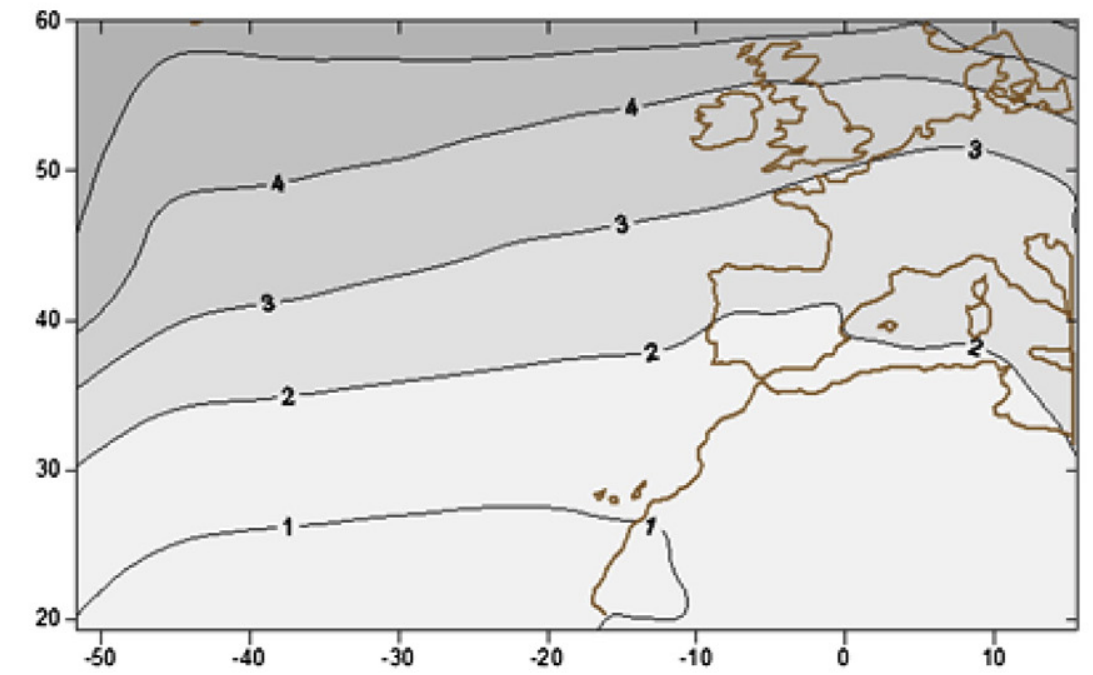

C

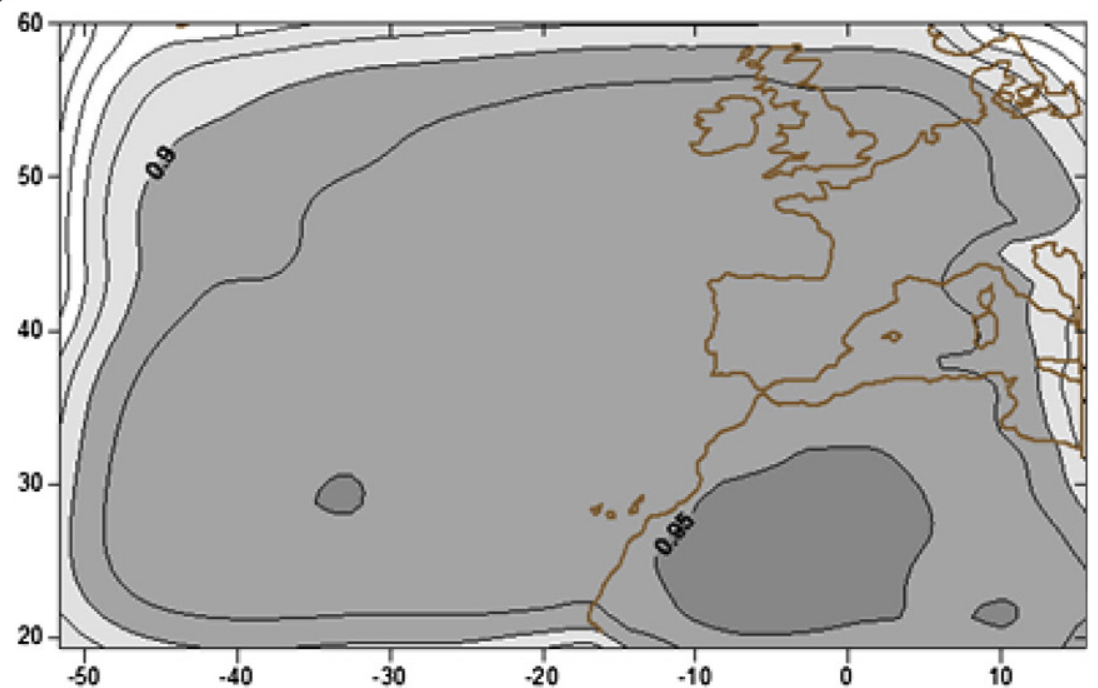

Fig. 8. Spatial distributions of: (a) bias (gpm), (b) rmse (gpm) and (c) correlation between the averaged Z1000 field obtained from the analog method, Z̃ 1000, and the input Z1000 field. 
growing. Understanding and assuming the rmse of a big quantity of analogs like the climatological error, it is again clear that the method improves the climatological skill. Therefore, the used distance to select the Z1000 analogs corresponds to the $d^{\prime}{ }_{t}$ (Fig. 6) and the best number of analogs to be used is found between 5 and 10 .

Additionally, rmse values between $Z \mathbf{Z} 1000$ and the input Z1000 field were obtained for the time period of the Z1000 field (Fig. 7). It can be noted the decrease of the errors as the time record increases, corresponding less errors to the Z1000 maximum length. Therefore, it is important the extent of the time series in this analog methodology. The higher the time record, the lower the model errors.

Some additional deterministic results have been also derived from the $\tilde{Z} 1000$ and the input Z1000 field (Fig. 8). Spatial distribution of bias presents, in general, low spatial values over all Z1000 spatial domain, being moderately remarkable the positive bias over the part of Europe (France, Germany and the Western Mediterranean area) and the negative one over the North Atlantic zone (Fig. 8a). The former values indicate overestimation of the method in calculating the analogs while the latter ones can be associated to the matched estimation of the North Atlantic Oscillation, NAO (Barnston and Livezey, 1997) by the methodology. Nevertheless, both positive and negative values are very small with an averaged spatial bias of $0.05 \mathrm{hPa}$, pointing that the analog $\tilde{Z} 1000$ reproduces realistically the input Z1000. Spatial rmse values (Fig. 8b) depict a gradient, showing the low values located in the southern Z1000 domain and the large values in the northern area. An averaged spatial rmse of $2.67 \mathrm{hPa}$ over the Z1000 area has been also derived. Finally, point-to-point correlations between the input Z1000 field and the averaged Z̃1000 have been also calculated (Fig. 8c). There are remarkable the high correlation values over all the domain, being the spatial correlation averaged over the Z1000 area of 0.92 . These high values indicate the good skill of the method in determining the analogs.

From the obtained results, it can be concluded that the procedure used in this paper to find analogs, reducing previously via PCA the dimensionality of the large-scale atmospheric data has been revealed as a good technique to find similar patterns to a particular one. As a result, similar atmospheric situations to any particular atmospheric situation to be modeled have been determined and from them, several and different wind fields (MWS and MGU) have been obtained and averaged to characterize and provide estimated wind fields in Spain.

\section{Evaluation of MWS and WGU analog estimations}

Once the Z1000 analogs throughout the time have been obtained, their corresponding dates present associated wind fields that finally allow us that an averaged estimated Spanish wind field can be obtained (Fig. 9). Here, both estimated wind variables (MWS and MGU) have been analyzed, taking into account both deterministic and probabilistic tools that assessing the accuracy and skill of the wind estimations.

Like in the $\mathrm{Z} 1000$ case and once the metric $d^{\prime}{ }_{t}$ has been selected, the procedure is replicated to the wind field taking into account the fixed analog approach. Averaged wind fields for both wind variables are estimated. As in Fig. 6 for Z1000, rmse values calculated between the averaged estimated wind data obtained from analogs and observational wind data are derived. The number of analogs for estimating the wind field in the ANPAF model has been also analyzed (not shown), finally obtaining 15 analogs as the optimum number.

Other deterministic results are also calculated for both wind variables (Table 1). Biases for MWS and WGU between the averaged wind obtained from the analog method and the observational wind fields present small values. Moreover, the absolute relative biases present values around $1.66 \%$ and $1.81 \%$ for WGU and MWS, respectively, indicating that the estimated analog wind reproduces pretty well the observational wind. The values point to significant relationships, that is, the input and the output data are strongly related. Therefore, the input in the model (Z1000) involves enough information in the output (Z1000) fields, and consequently in the wind results. Although the rmse values are in general small, the results of MWS and WGU are not comparable between them, because of the different range of variability of each variable. On the other hand, the moderately high values of correlation highlight the existent relationships between the input and the output fields, there by emphasizing a degree of skill of the method in estimating the MWS and the WGU at Spain.

From the deterministic point of view, different statistical tools have been used, comparing the results of the MWS and the WGU. On the other hand, the probabilistic performance of wind estimations can be evaluated following the

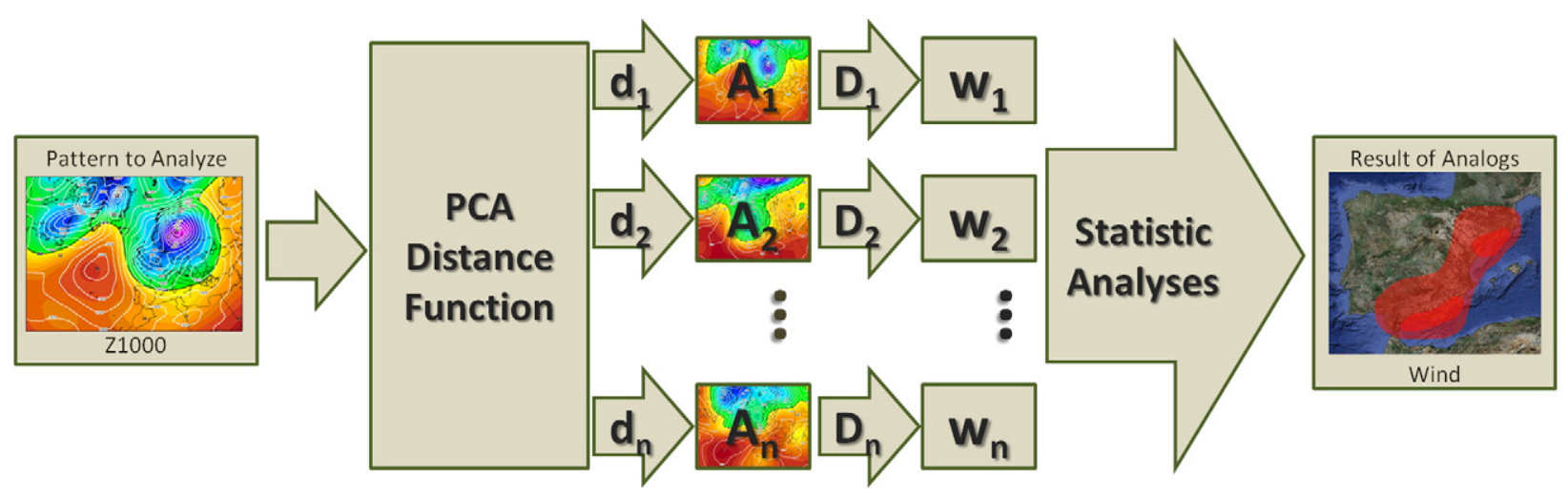

Fig. 9. Illustration of the wind field estimation by analog searching. 
Table 1

Spatial averaged bias $\left(\mathrm{ms}^{-1}\right)$, rmse $\left(\mathrm{ms}^{-1}\right)$ and correlation obtained from the estimated wind versus the observational data.

\begin{tabular}{llll}
\hline & Bias & rmse & $\mathrm{r}$ \\
\hline MWS & -0.10 & 1.43 & 0.60 \\
WGU & -0.20 & 3.01 & 0.71 \\
\hline
\end{tabular}

difference between a forecasted probability distribution and the observed probability distribution. Thus, several probabilistic verification results are also shown in addition to the deterministic verification.

A more detailed way of analyzing the analog wind spread is to construct a rank histogram or the so called Talagrand di-

a

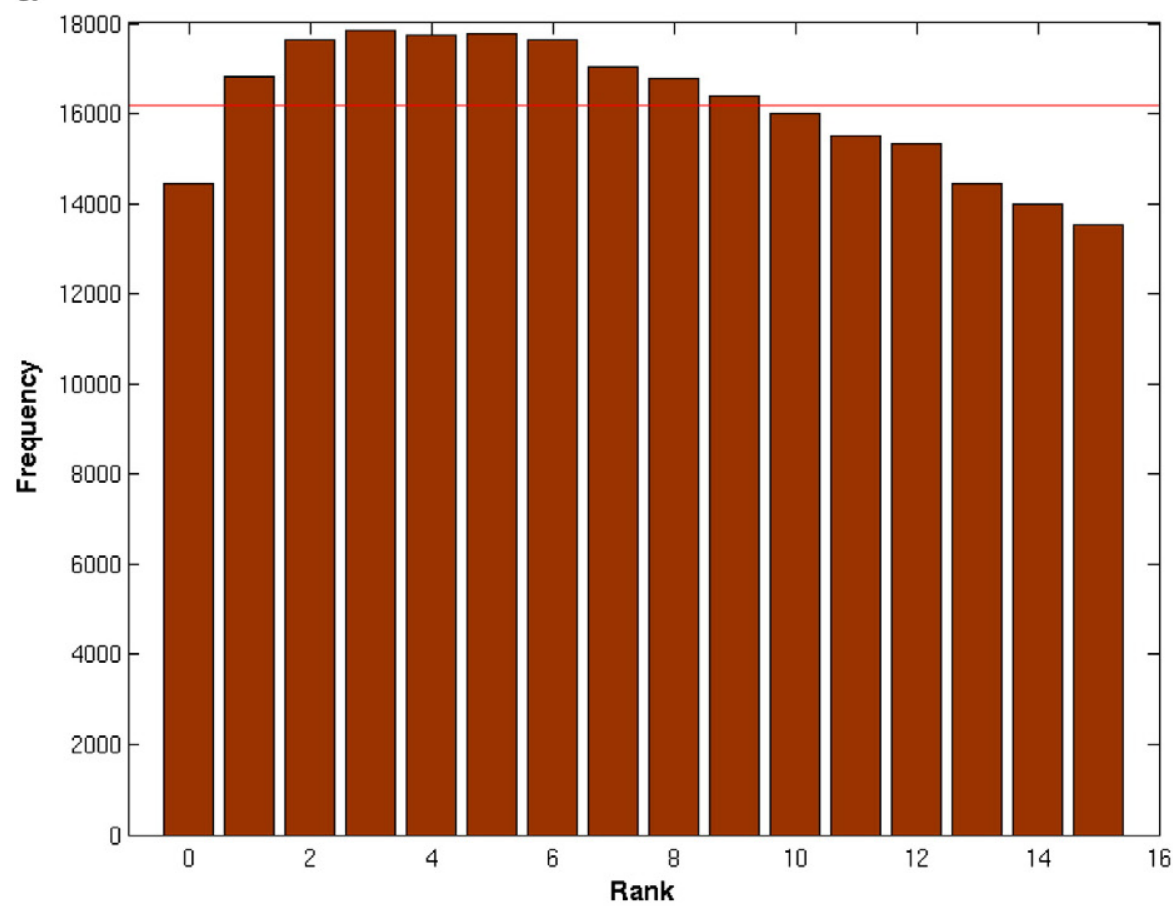

b

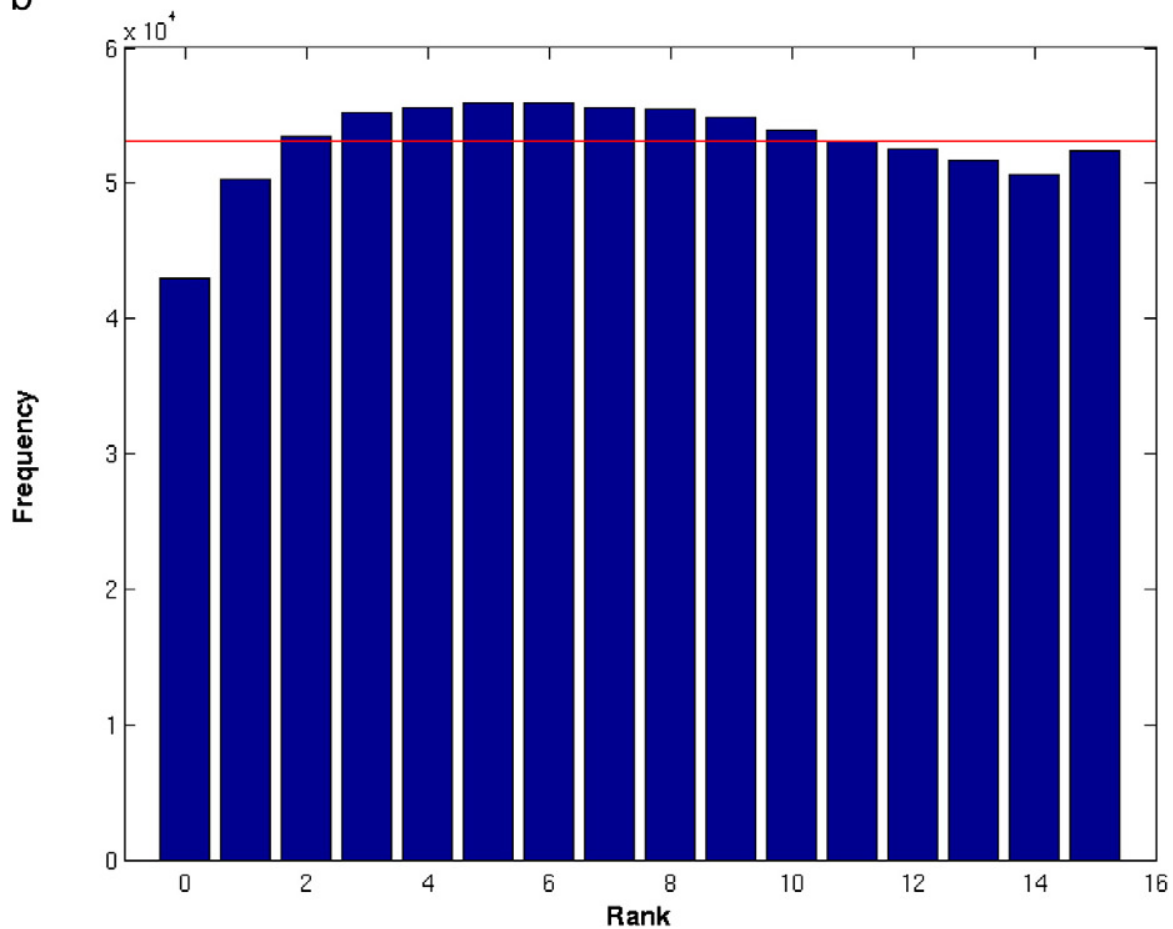

Fig. 10. Illustrations of the rank histograms of: (a) MWS and (b) WGU. 
a

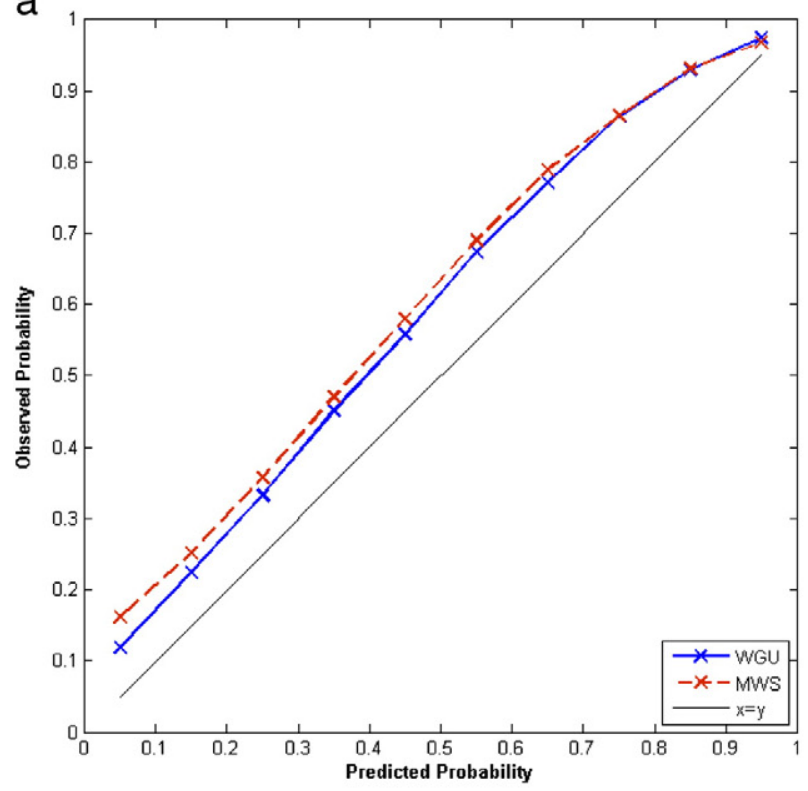

C

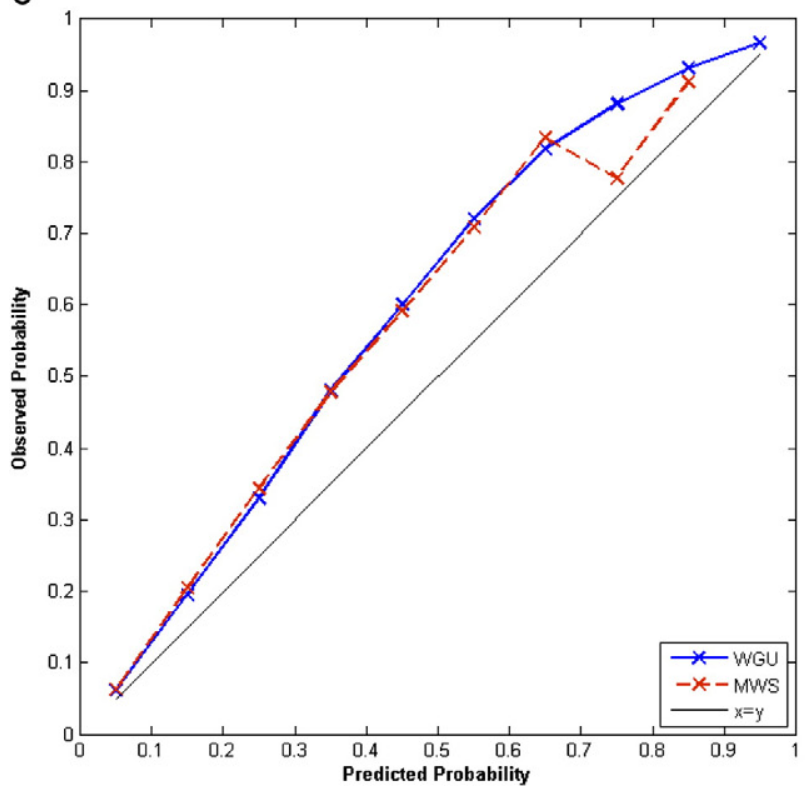

b

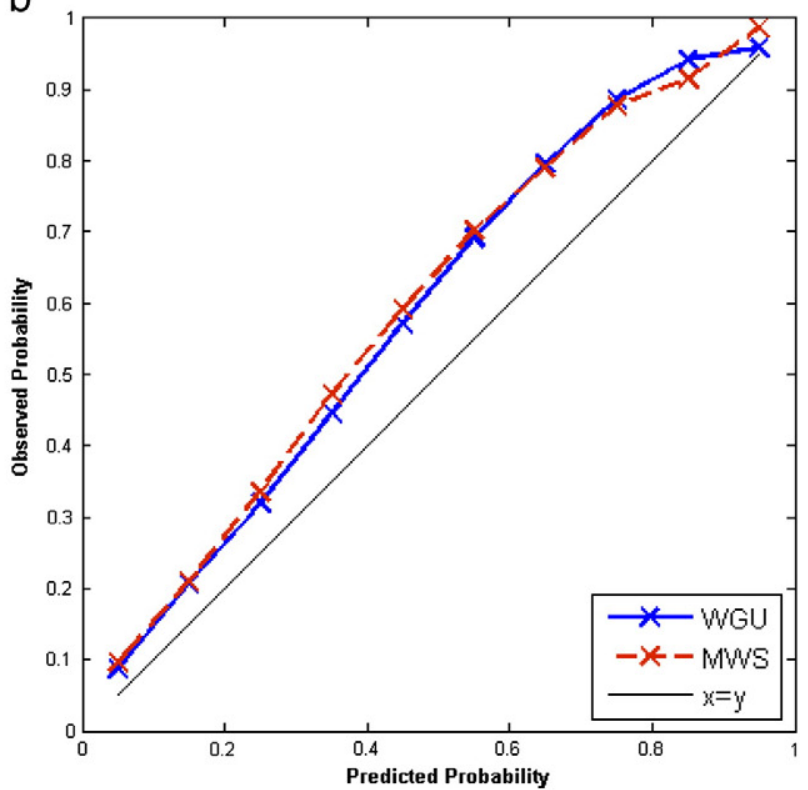

d

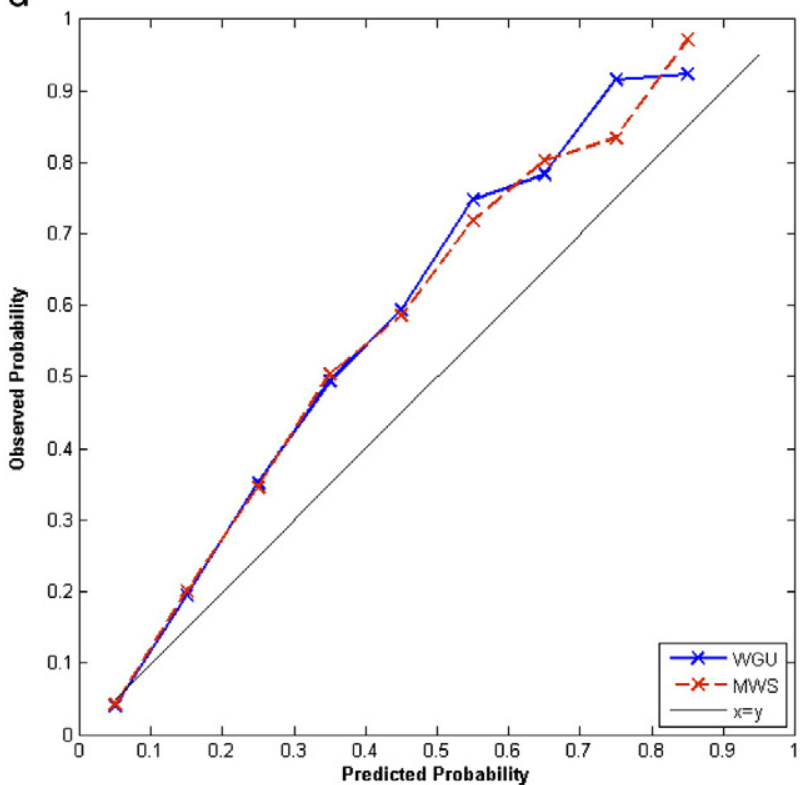

Fig. 11. Reliability diagrams of MWS (red dashed line) and WGU (blue continuous line) derived for different thresholds: (a) $\sigma=0$, (b) $\sigma=0.5$, (c) $\sigma=1.0$, (d) $\sigma=1.5$, (e) $\sigma=2.0$ and (f) $\sigma=2.5$.

agram (Talagrand et al., 1997). The Talagrand diagrams are mainly used as verification tools in Ensemble Prediction Systems, EPS, and utilized to analyze the EPS spread (Hamill, 2001). In this paper, rank histograms are used for corroborating the final selected analogs. Understanding the number of analogs as a statistical pool of similar atmospheric situations, the rank histogram could be applied to assessing how the number of analogs is representative of an input situation. In this way, depending of the Talagrand diagram shape, the selected number of analogs will be statistically significant and characteristic of the input pattern. Briefly, in a perfect model the verifying analysis is equally likely positioned between any two ordered adjacent analogs, including cases when the analysis lies outside the model range on either side of the distribution. In general, as the diversity among the analogs increases, there are more possibilities in capturing the observed data. The forecast diversity is expressed by the forecast spread. If the spread is too large, the forecast uncertainty is also large, and then, the confidence diminishes. The desirable situation is to have the smaller spread possible with low outlier rate. In both cases, the Talagrand histogram will have a concave shape instead of a $U$-shape, indicating these non-uniform shapes under/over dispersion and bias. In our case, a $\cup$-shape would be associated with very small 

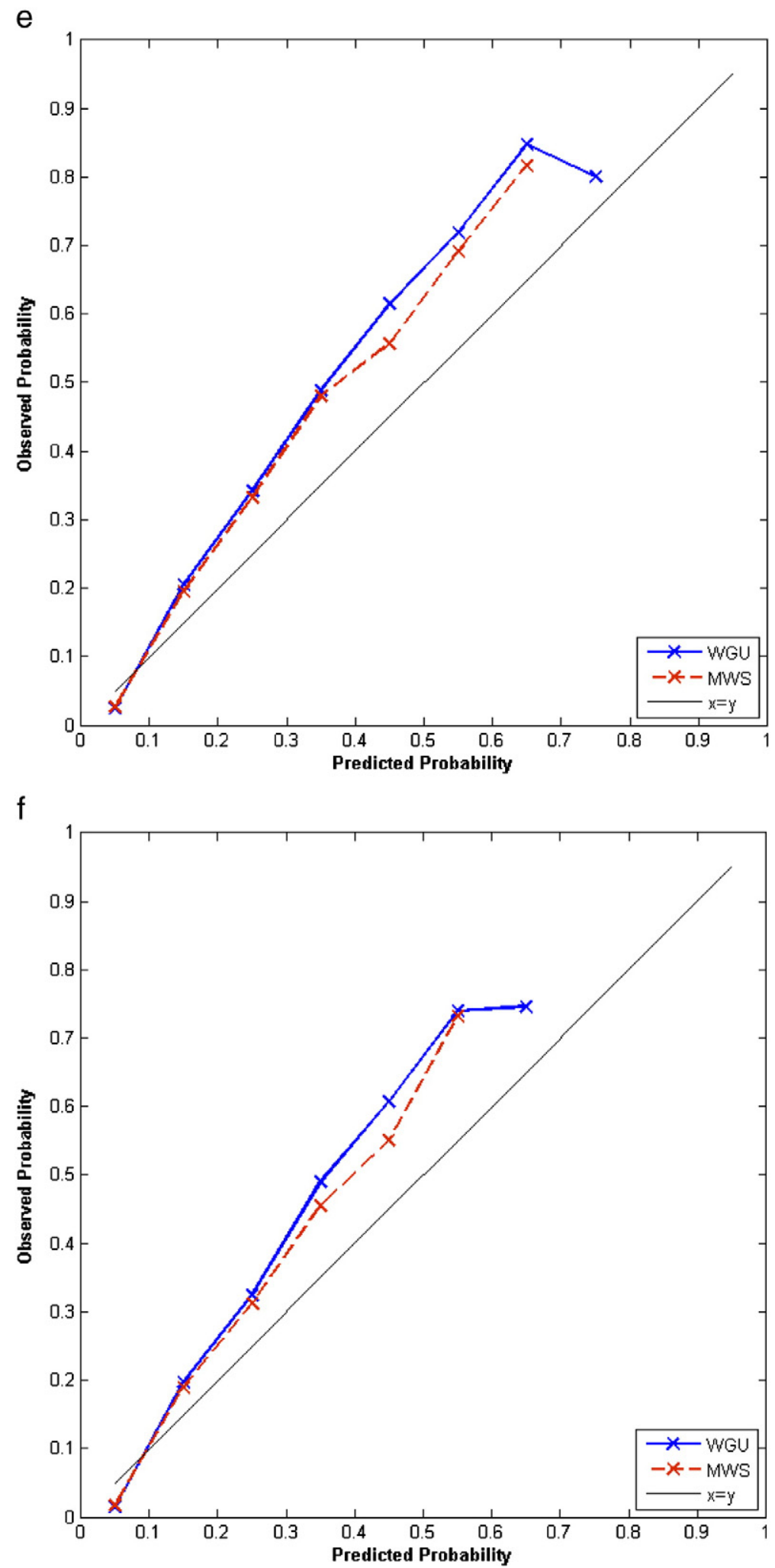

Fig. 11 (continued). 
number of analogs while a $\cap$-shape would indicate a used large quantity of analogs. Generally, in a good forecast model, all selected analogs should have an equal ability to capture the observations, being thus the Talagrand diagram flat. In our case, the MWS rank histogram (Fig. 10a) shows a slightly $\cap$-shaped, indicating a large spread, with many observations falling between the extremes of the analog estimations. Because of the asymmetric shape of the diagram (with higher values of frequency between the 1 and 8 bins), it can be noted that the analog model presents some underprediction of the MWS values. On the other hand, the WGU rank histogram (Fig. 10b) depicts a general quite better behavior showing a flatter distribution than the MSW diagram. Moreover, while the MWS diagram and the WGU show an asymmetric shape more pronounced in its left side, i.e., for the lower values, the WGU Talagrand presents a quasi-flat shape corresponding to the higher values.

Because of the rank histogram can only evaluate the level of consistency of the model, it must be used together with other forecast tools in order to generate a more complete picture of the quality of the model performance; in consequence, other scores that measure skill and reliability will be additionally used. The reliability curve is a diagram where the observed frequency is plotted against the forecast probability. With the reliability diagram, the observed and estimated probability density functions can be compared, assessing the skill of the model in estimating the probabilities. The best curve in the diagram is a line along the $45^{\circ} \mathrm{di}-$ agonal; a deviation from the diagonal indicates conditional bias: any deviation below the diagonal represents too high forecast probabilities; on the contrary, points above diagonal indicate forecast probabilities that are too low. In this paper, reliability curves have been computed taking into account several thresholds corresponding with the values of the standard deviation, $\sigma$, of the original data, both MWS and WGU. For all the thresholds, (Fig. 11), the reliability curves deviate in general from the best line, being the model forecast probability smaller than observed frequency. This situation indicates underestimation of the observational wind frequencies in both variables. Again, the WGU behavior is quite better than the MWS one. It is worth noting the resemblance of the underestimation of the probabilistic values in all reliability diagrams for all thresholds except for the small probabilistic values in Fig. 11c-f, being remarkable the similarity up to probability values of $20 \%$. It points out that the ANPAF model reasonably matches the observational and forecast data in such frequencies.

Additionally, the Brier Score (BS) and the Brier Skill Score (BSS) are here used and derived with respect to the climatological probability for different thresholds (Brier, 1950). The BS shows that the goodness of the model performance, as measured by this score is very similar to the different thresholds. The BSS proves that the model generates forecasts with better skill than the climatology. The lower the Brier Score manifests the better forecast; so, as much as the BSS tends to the unity, better is the model skill. Thus, the BSS is typically defined as the relative probability score compared with the probability score of a reference forecast. In order to assess the accuracy and skill of all obtained wind estimations from the analog model, the BSS has been also derived in this paper for values of the standard deviation of the original data, both MWS and WGU. Thus, not only the model mean skill is analyzed, but the estimated tails are also evaluated. The BS of reference, $B S_{\text {ref, }}$ used in this work corresponds to the climatological value. The $B S_{\text {ref }}$ has been obtained using the observational climatological frequencies taking into account such thresholds. The areal averaged BSSs for all selected thresholds show values greater than zero and indicate that the forecasts improve the

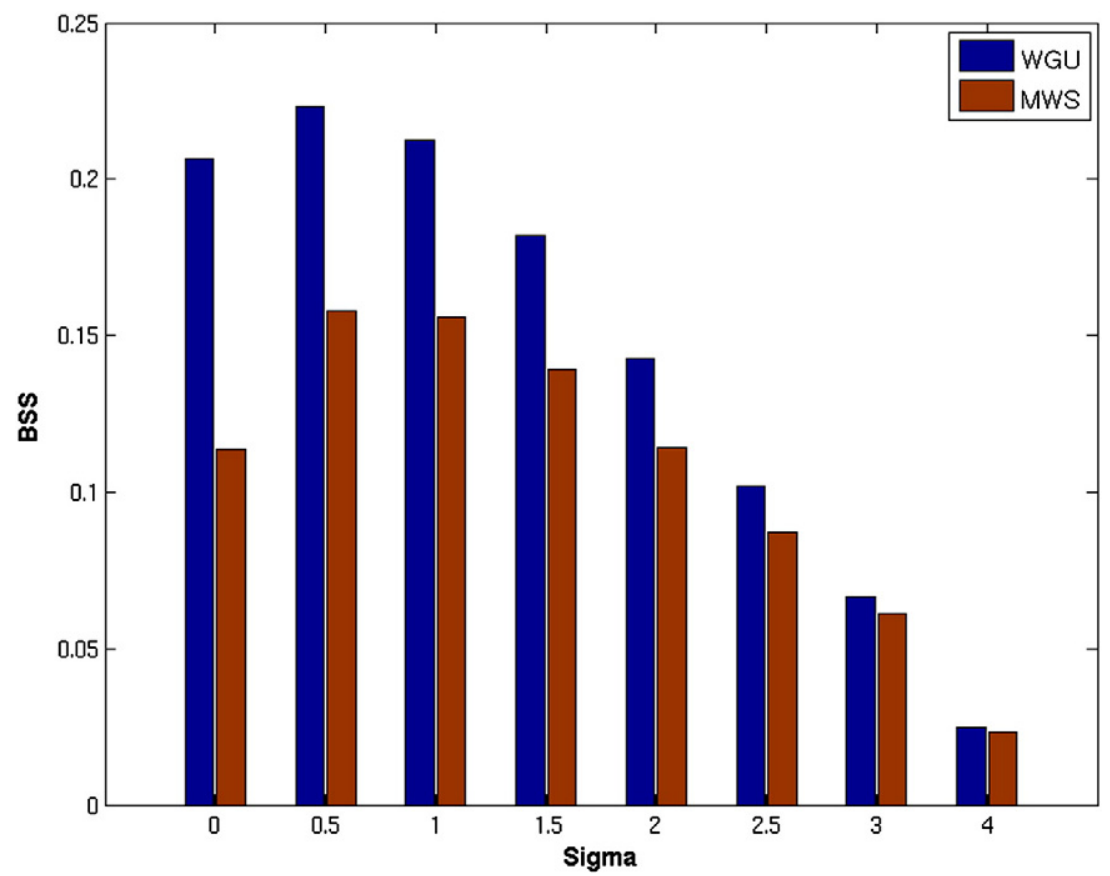

Fig. 12. Illustration of BSS values for different values of $\sigma$ : red bars (MWS) and blue bars (WGU). 
a

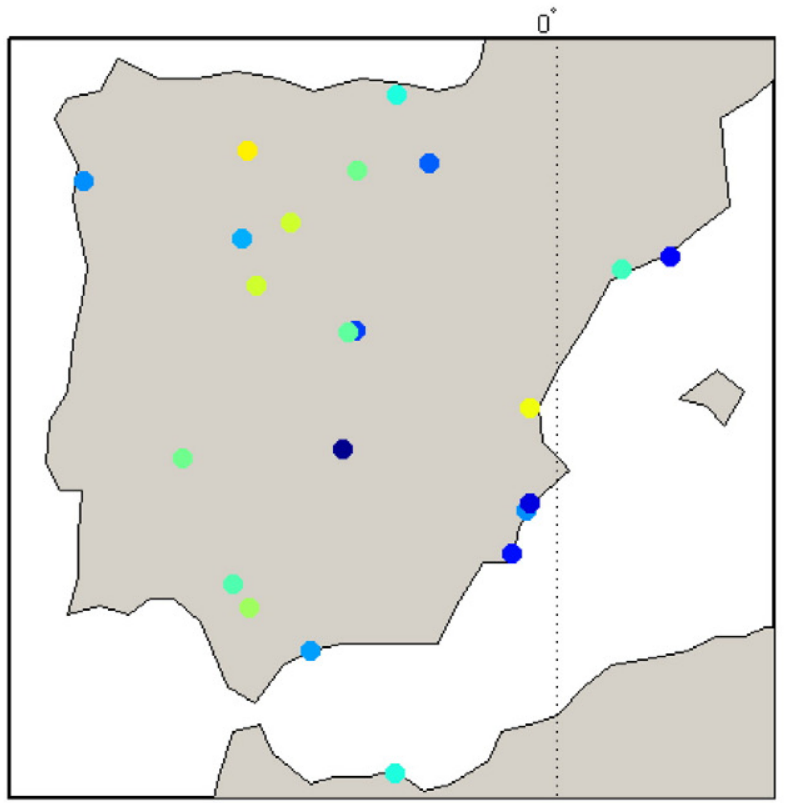

b

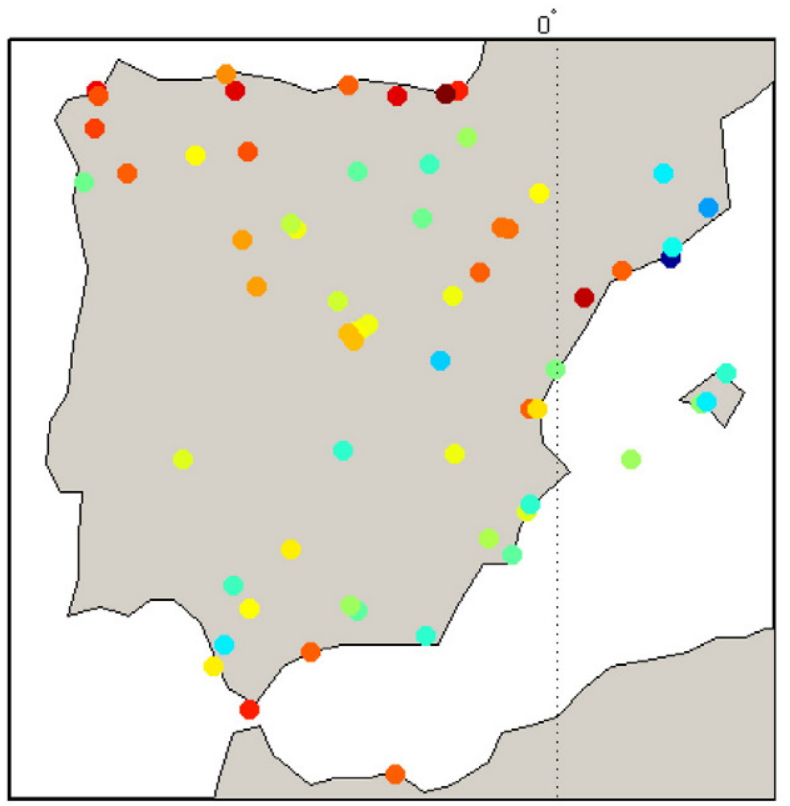

Fig. 13. Spatial distributions of BSS for $\sigma=0$ of: (a) MWS and (b) WGU stations shown in Fig. 1.

climatologic model. The BSSs for several os show an asymmetric shape (Fig. 12), being the best results associated with the value of $\sigma=0.5$ in both cases, although the WGU result is better than the MWS one. The analogs obtained from the ANPAF model shows the best results for $\sigma$ values ranging between 0.5 and 1.5. For extreme values, associated with the $\mathrm{BSS} \approx 0.12$ for $\sigma \geq 2$, a gust range of $16-26 \mathrm{~ms}^{-1}$ is recorded, spreading the high values over the Ebro Valley and the Gibral-

Fig. 14. (a) Spatial patterns of the fifth wind speed PC. The positive (negative) correlations are solid (dashed). (b) Positive composite map of the Z1000 (gpm) conditioned by the highest scores of the fifth MWS PC. (c) Positive composite map of MWS (ms ${ }^{-1}$ ) with shaded areas highlighting values higher than $5 \mathrm{~ms}^{-1}$. Crosses indicate the MWS stations. 
a

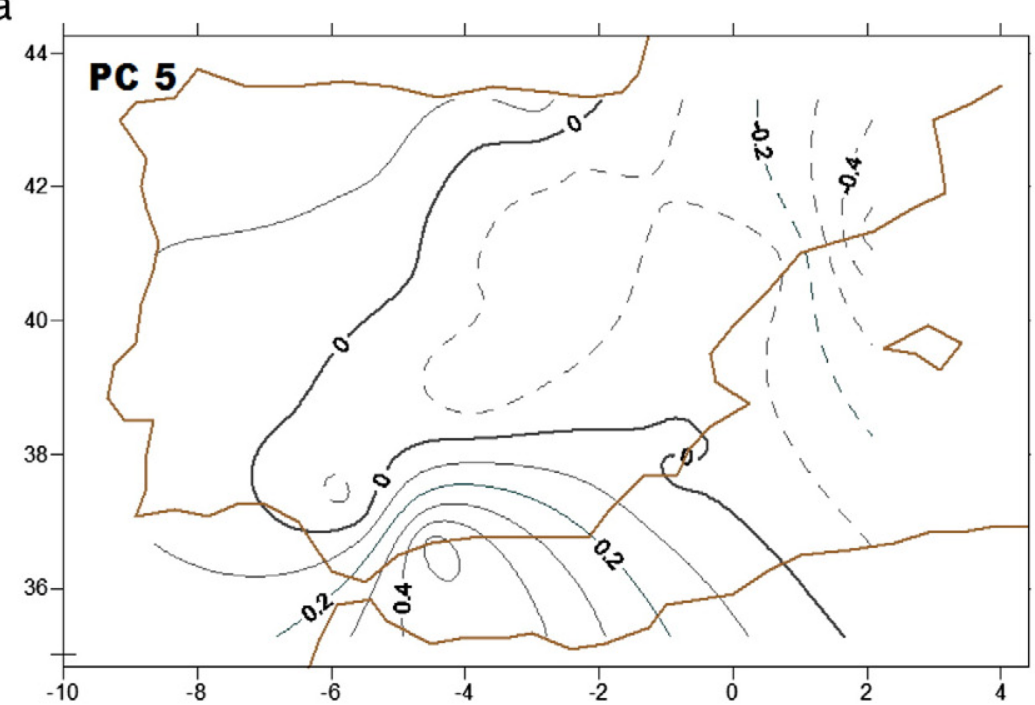

b

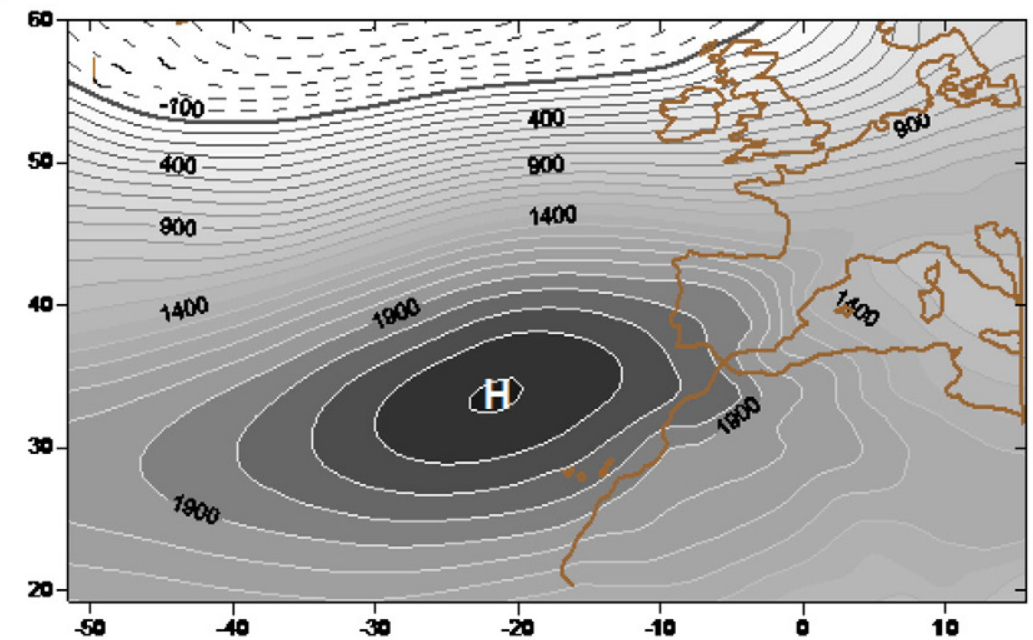

C

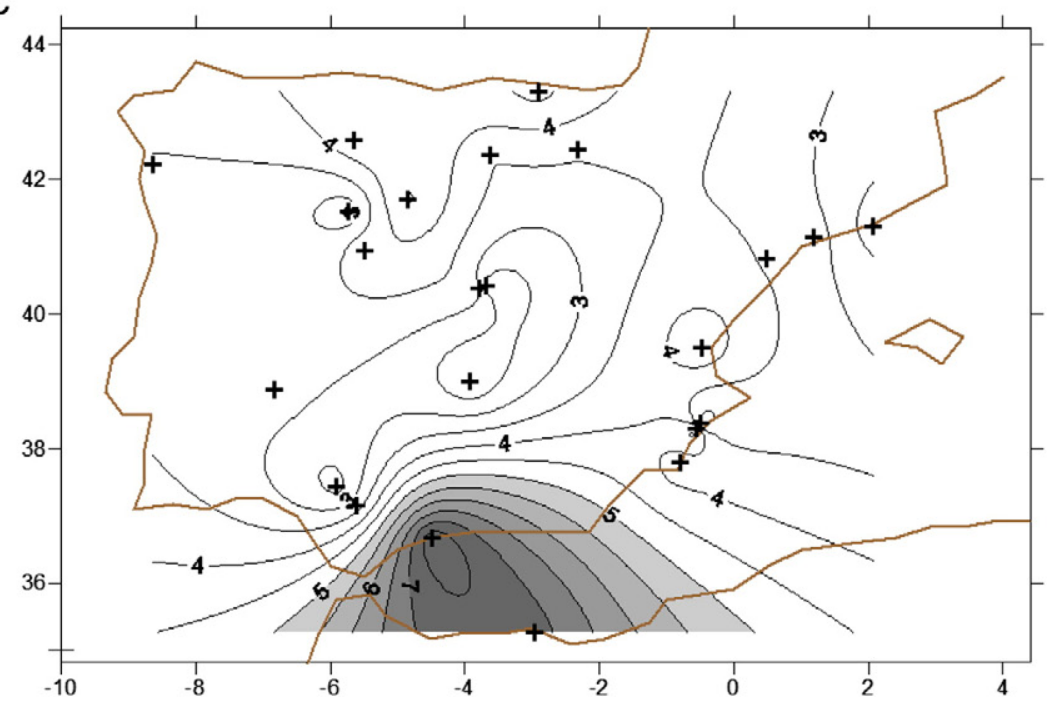


tar Strait $\left(\approx 93 \mathrm{~km} \mathrm{~h}^{-1}\right)$. It is worth noting that for extreme values, MWS and WGU, show similar behavior.

The BSSs for MWS and WGU are also derived for mean values (Fig. 13) and for $\sigma=0.5$ (not shown) in each Spanish station. The BSS spatial distribution is shown more clearly in the WGU case than in the MWS one for both thresholds, since the WGU database includes more stations than the MWS dataset. The MWS BSS results (Fig. 13a) are again worse than the corresponding WGU ones (Fig. 13b) in the whole domain. For both thresholds, the BSS spatial distribution presents the best values $(\approx 0.25)$ over Northern Iberia (Fig. 13b), while the Spanish remainder stations show small values. It means that the atmospheric situations coming from the Atlantic Ocean are better to predict mean wind and gusts in the Northern Peninsula. It is worth also to note high WGU BSS values located over the Gibraltar Strait and along the Ebro Valley zones, although smaller ones in the MWS case. On the contrary, the worse BSS estimations are mainly located on northern Catalonia for both $\sigma=0.5$ values and for the mean values.

\section{Conclusions and discussion}

Daily mean wind speeds and wind gusts observed over Spain have been estimated by means of an analog method. Three data sets have been used: daily 1000 geopotential height (Z1000) field over the North Atlantic and the observational daily mean wind speed (MWS) and gust wind speeds (WGU) over Spain. In the framework of the European Project SafeWind, a statistical downscaling model (ANPAF: ANalog PAttern Finder) for diagnosing large-scale atmospheric circulation patterns and subsequently estimating extreme wind probabilities has been developed by the authors.

From the ANPAF model, similar atmospheric situations were obtained and from them, several and different wind fields (MWS and MGU) have been subsequently obtained and averaged, characterizing and giving both Spanish estimated wind fields. In order to assess the accuracy and skill of the wind estimations, these fields have been analyzed by means of both deterministic and probabilistic tools. Deterministic results point to a reasonably method skilful in estimating the MWS and the WGU fields in Spain. Concerning some probabilistic tools, rank histograms, reliability curves and skill scores have been used assessing the model skill in estimating wind data.

For the MWS rank histogram, large spread has been observed, highlighting the presence of several observations located between the extremes of the analog estimations. The MWS Talagrand also shows an asymmetric shape, pointing out some underprediction of the MWS values. The WGU rank histogram has shown flatter distribution than the MSW one, illustrating a general pretty better behavior. Reliability curves have been also used for several thresholds corresponding with multiple values of the standard deviations of the original data, deviating in the two wind variable cases from the best line. There is underestimation of the observational wind frequencies in both variables. Again, the WGU behavior is quite better than the MWS one. For high threshold values, the resemblance of the probability values up to frequencies around $20 \%$ is noteworthy, highlighting that the ANPAF model reasonably matches the observational and forecast data in such low frequencies. Moreover, MWS and WGU areal averaged BSSs have been obtained, evaluating the model skill in its mean values and in its extreme range for also several multiple values of os. The BSSs for several os have shown an asymmetric shape, being the best results for $\sigma$ values ranging between 0.5 and 1.5 and the maxima for $\sigma=0.5$. The WGU BSS result is better than the MWS one. BSS values diminish for extreme values, although both variables show similar behavior.

Additionally, the Spanish spatial distributions of the MWS and WGU BSSs have been also derived for the $\sigma=0$ and 0.5. While most of Spain shows small values for both thresholds, the best BSS results have been located over North Spain, stressing that the whole procedure is able to estimate the atmospheric situations coming from the Atlantic Ocean and subsequently to predict reasonably mean winds and gusts in the Northern Peninsula. Three are remarkable values along the Ebro Valley and over the Gibraltar Strait area, being more noticeable in the WGU since its dataset presents a better spatial coverage than the MWS database. The moderately high BSS values over the Gibraltar area indicate significant relationships between the input (Z1000) and the output (winds) fields. Pascual et al. (2010) have analyzed the wintertime linkage between the observed MWS over Spain and the Z1000 through the PCA methodology. Five leading modes for the wind dataset, explaining more than $66 \%$ of the total variability, can be highlighted (Kaiser, 1960). In the obtained MWS PC2 (not shown), there were two zones showing a west-east isoline distribution, with the highest negative loading values in western Atlantic Iberia and the highest positive correlation values over some Mediterranean areas, Catalonia and the Gibraltar Strait. However, it was in the obtained MWS PC5 pattern (Fig. 14a) where the high correlation values centered on the eastern Gibraltar Strait are remarkable. Although the results are only shown for wintertime, this MWS pattern has been also obtained for the remainder seasons (not shown), underlining that the abovementioned BSS nucleus located over the Strait is noteworthy. Martín et al. (2011a) and Martín et al. (2011b) examined true relationship between large-scale atmospheric field and wind gusts through composite maps, giving an average atmospheric circulation associated with coherent wind gust variability in Spain. Here, in order to examine the atmospheric circulation features associated with the winter patterns of wind speed, a set of positive and negative composite plots of both Z1000 and MWS have been also constructed from the dates associated with 5 and 95 percentiles of the scores of the time series obtained of the PCA. Positive composite of the Z1000 field associated with the dates corresponding to the $5 \%$ highest scores of the MWS PC5 time series shows (Fig. 14b) a nucleus of high Z1000 values situated southwest of Iberia, which promote air mass advection over the south of Iberia. This atmospheric configuration favors strong northern winds over southern areas of Spain, in particular, in the Gibraltar Strait as can be seen in the corresponding MSW composite (Fig. 14c). Therefore, such weather situations coming from the Atlantic Ocean can be considered as a reasonably good input in the analog procedure to predict winds in the Gibraltar Strait area.

It may be concluded that the process used in this paper to find analogs, based on initially reducing the dimensionality of the large-scale atmospheric data after obtaining PCs, and 
subsequently applying the ANPAF analog model, has been revealed as a good technique to find similar atmospheric patterns and from them, to estimate wind fields. Although the analyses have shown that the model shows the best results in the atmospheric field data, the wind results could be improved with the use of statistical methods based on combining predictive distributions from different sources. However, this approach is beyond this paper, although works in these points are in progress. It is also noteworthy to comment that the used methodology does not present any constraint to be used in other regions of the Earth, beyond the selection of the window in the large-scale data in order to capture significant signals associated with the regional data.

\section{Acknowledgments}

This work has been partially supported by the research projects AYA2011-29967-C05-02, CGL2007-61328, UE Safewind G.A. No. 21374, VA025A10-2 and CGL2011-25327. The authors wish to thank the Spanish Meteorological Agency (AEMET: Agencia Estatal de Meteorología) for providing the Spanish wind datasets and the European Centre for Weather Medium Forecast (ECWMF) for providing the ERA40 data.

\section{References}

Aznar, R., Sotillo, M.G., Martín, M.L., Somot, S., Valero, F., 2010. Comparison of model and satellite-derived long-term precipitation databases over the Mediterranean basin: a general overview. Atmos. Res. 99, 170-184.

Barnett, T.P., Preinsendorfer, R.W., 1978. Multifield analog prediction of short-term climate fluctuations using a climate state vector. J. Atmos. Sci. 35, 1771-1787.

Barnston, A.G., Livezey, R.E., 1997. Classification, seasonality and persistence of low-frequency atmospheric circulation patterns. Mon. Weather Rev. $115,1083-1126$.

Brier, G.W., 1950. Verification of forecasts expressed in terms of probabilities. Mon. Weather Rev. 78, 1-3.

Busuioc, A., Dealing, C., Hellström, C., 2008. Performance of statistical downscaling models in GCM validation and regional climate change stimates: application for Swedish precipitation. Int. J. Climatol. 21, 557-578.

Cofiño, A. S. 2004. Técnicas estadisticas y neuronales de agrupamiento adaptativo para la predicción probabilística de fenómenos meteorológicos locales. Aplicación en el corto plazo y en la predicción estacional. Tesis doctoral, Universidad de Cantabria.

Corte-Real, J., Quian, B., Xu, H., 1998. Regional climate in Portugal: precipitation variability associated with large-scale atmospheric circulation. Int. J. Climatol. 18, 619-635.

Dool van den, H.M., 1989. A new look at weather forecasting though analogs. Mon. Weather Rev. 177, 2230-2247.

Dool van den, H.M., 1994. Searching for analogs, how long must we wait? Tellus 46A, 314-324.

Fernandez, J., Saenz, J., 2003. Improved field reconstruction with the analog method: searching the CCA space. Climate Res. 24, 199-213.

Fraedrich, K., Rückert, B., 1998. Metric adaption for analog forecasting. Phys. A 253, 379-393.

Fraedrich, K., Raible, C.C., Sielmann, F., 2003. Analog ensemble forecasting of tropical cyclone tracks in the Australian region. Weather Forecast. 18, 3-11.

García-Ortega, E., López, L., Sánchez, J.L., 2011. Atmospheric patterns associated with hailstorm days in the Ebro Valley, Spain. Atmos. Res. 100, 401-427.

Gibson, J.K., Kallberg, P., Uppala, S., Hernandez, A., Ñomura, A., Serrano, E., 1997. ERA description. Technical Report Re-analysis Project Report Series 1. ECMWF, Reading, UK.

Gutierrez, J.M., Cano, R., Cofiño, A.S., Rodriguez, M.A., 2004. Clustering methods for statistical downscaling in short-range weather forecast. Mon. Weather Rev. 132, 2169-2183.

Hamill, T.M., 2001. Interpretation of rank histograms for verifying ensemble forecasts. Mon. Weather Rev. 129, 550-560.

Hastie, T., Tibshirani, R., Friedman, J., 2001. The elements of statistical learning. Springer, New York.
Joliffe, I.T., 1986. Principal Component Analysis. Springer, New York, p. 271.

Kaiser, H.F., 1960. The application of electronic computers to factor analysis. Educ. Psychol. Meas. 20, 141-151.

Li, Y., Smith, I., 2009. A statistical downscaling model for southern Australia winter rainfall. J. Climate 22, 1142-1158.

Lorenz, E.N., 1969. Atmospheric predictability as revealed by naturally occurring analogues. J. Atmos. Sci. 26, 636-646.

Luna, M.Y., Martín, M.L., Valero, F., González-Rouco, F., 2001. Wintertime Iberian Peninsula precipitation variability and its relation to North Atlantic Atmospheric circulation. In: Brunet, M., López, D. (Eds.), Detecting and modelling regional climate change and associated impacts. SpringerVerlag, Berlin, pp. 369-376.

Martín, M.L., Fenoy, M.M., Luna, M.Y., Morata, A., Valero, F., Quesada, V., 2001. Estudio estadístico de la precipitación en la Península Ibérica mediante transformadas wavelet. XXVI Congreso Nacional de Estadística e Investigación Operativa. Pub. Universidad de Jaén. (10 pp.).

Martín, M.L., Luna, M.Y., Morata, A., Valero, F., 2004. North Atlantic teleconnection patterns of low-frequency variability and their links with springtime precipitation in the western Mediterranean. Int. J. Climatol. 24, 213-230. doi:10.1002/joc.993.

Martín, M.L., Santos-Muñoz, D., Morata, A., Luna, M.Y., Valero, F., 2006. An objectively selected case heavy rain event in the Western Mediterranean Basin: a study through diagnosis and numerical simulations. Atmos. Res.. doi:10.1016/j.atmosres.2005.12.002) 81, 187-205

Martín, M.L., Santos-Muñoz, D., Valero, F., Morata, A., 2010. Evaluation of an ensemble precipitation prediction system over the Western Mediterranean area. Atmos. Res. 98, 163-175. doi:10.1016/j.atmosres.2010.07.002.

Martín, M.L., Valero, F., Morata, A., Luna, M.Y., Pascual, A., Santos-Muñoz, D., 2011a. Springtime coupled modes of regional wind in the Iberian Peninsula and large-scale variability patterns. Int. J. Climatol. 31, 880-895. doi:10.1002/joc.2127.

Martín, M.L., Valero, F., Pascual, A., Morata, A., Luna, M.Y., 2011b. Springtime connections between the large-scale sea level pressure field and gust wind speed over Iberia. Nat. Hazards Earth Syst. Sci. 11, 191-203.

Morata, A., Martín, M.L., Luna, M.Y., Valero, F., 2006. Self-similarity patterns of precipitation in the Iberian Peninsula. Theor. Appl. Climatol. 85, 41-59. doi:10.1007/s00704-005-0175-7.

Morata, A., Martín, M.L., Sotillo, M.G., Valero, F., Luna, M.Y., 2008. Iberian autumn precipitation characterization through observed, simulated and reanalysed data. Adv. Geosci. 16, 49-54www.adv-geosci.net/16/49/ 2008/.

Mosmann, V., Castro, A., Fraile, R., Dessensc, J., Sanchez, J.L., 2004. Detection of statistically significant trends in the summer precipitation of mainland Spain. Atmos. Res. 70, 43-53.

Palutikof, J.P., Kelly, P.M., Davies, T.D., Halliday, J.A., 1987. Impacts of spatial and temporal windspeed variability on wind energy output. J. Appl. Meteorol. 26, 1124-1133.

Pascual, A., Martin, M.L., Valero, F., Santos-Muñoz, D., Morata, A., Luna, M.Y., 2010. Development of an analogous model for wind prediction using principal components. The SAFEWIND Workshop. Oldemburg, Germany. ((in www.safewind.eu), 22pp.).

Paul, S., Liu, C.M., Chen, J.M., Lim, S.H., 2008. Development of a statistical downscaling model for projecting monthly rainfall over east Asia from a general circulation model output. J. Geophys. Res. 113, D15117.

Preisendorfer, R.W., 1998. Principal Component Analysis in Meteorology and Oceanography. Elsevier Science Publishers BV, Amsterdam, p. 425.

Sievers, O., Fraedrich, K., Raible, C.C., 2000. Self-adapting analog ensemble predictions of tropical cyclone tracks. Weather Forecast. 15, 623-629.

Simmons, A.J., Gibson, J.K., 2000. The ERA-40 Project Plan. ERA-40 Project Report Series No. 1. ECMWF, Reading, UK.

Sordo, C. M. 2006. Técnicas estadísticas para la proyección local de la predicción meteorológica estacional. Métodos, validación y estudios de sensibilidad. Tesis doctoral, Universidad de Cantabria, 170 pp.

Sotillo, M.G., Martín, M.L., Valero, F., Luna, M.Y., 2006. Validation of an homogeneous 41-year (1961-2001) winter precipitation hindcasted dataset over the Iberian Peninsula: assessment of the regional improvement of global reanalysis. Clim. Dynam. 27, 627-645.

Talagrand, O., Vautard, R., Strauss, B., 1997. Evaluation of probabilistic prediction systems. Proc. Workshop on Predictability, pp. 1-25.

Thuillier, R.H., 1987. Real-time of local wind patterns for application to nuclear-emergency response. Bull. Am. Meteorol. Soc. 68, 1111-1115.

Trigo, R.M., DaCamara, C.C., 2000. Circulation weather types and their influence on the precipitation regime in Portugal. Int. J. Climatol. 20, $1559-1581$.

Valero, F., Luna, M.Y., Martín, M.L., Morata, A., González-Rouco, F., 2004. Coupled modes of large-scale climatic variables and regional precipitation in the Western Mediterranean in autumn. Clim. Dynam. 22, 307-323. doi:10.1007/s00382-003-0382-9. 
Valero, F., Martín, M.L., Sotillo, M.G., Morata, A., Luna, M.Y., 2009. Characterization of the autumn Iberian precipitation from long-term data sets: comparison between observed and hindcasted data. Int. J. Climatol. 29, 527-541. doi:10.1002/joc.1726.

Vrac, M., Stein, M., Hayhoe, K., 2007. Statistical downscaling of precipitation through nonhomogeneous stochastic weather TYPING. Climate Res. 34 169-184.

Wilby, R.L., Wigley, T., 1997. Downscalling general circulation model output. A review of methods and limitations. Prog. Phys. Geog. 21, 530-548.

Wilby, R.L., Wigley, T., Conway, D., Jones, P.D., Hewitson, B.C., Main, J., Wilks, D.S., 1998. Statistical downscaling of general circulation model output: a comparison of methods. Water Resour. Res. 34, 2995-3008.

Xoplaki, E., Gonzalez-Rouco, J.F., Gyalistras, D., Luterbacher, J., Rickli, R., Wanner, H., 2003a. Interannual summer air temperature variability over Greece and its connection to the large-scale atmospheric circulation and Mediterranean SSTs 1950-1999. Clim. Dynam. 20, 537-554.
Xoplaki, E., Gonzalez-Rouco, J.F., Luterbacher, J., Rickli, R., Wanner, H., 2003b. Mediterranean summer air temperature variability and its connection to the large-scale atmospheric circulation and SSTs. Clim. Dynam. 20, 723-739.

Xoplaki, E., Gonzalez-Rouco, J.F., Luterbacher, J., Wanner, H., 2004. Wet season Mediterranean precipitation variability: influence of large-scale dynamics and predictability. Clim. Dynam. 23, 63-78.

Zhu, M., Lakshmanan, Valliappa, Zhang, Pengfei, Hong, Yang, Cheng, Kesong, Chen, Sheng, 2011. Spatial verification using a true metric. Atmos. Res. 102, 408-419.

Zorita, E.Y., von Storch, H., 1999. The analog method as a simple statistical downscaling technique: comparison with more complicated methods. J. Climate 12, 2474-2489.

Zuranski, J.A., Jaspinka, B., 1996. Directional analysis of extreme wind speeds in Poland. J. Wind Eng. Ind. Aerodyn. 65, 13-20. 